\title{
The Effect of Review Writing on Learning Engagement in Channel Partner Relationship Management
}

Citation for published version (APA):

Aguirre Lopez, E., Grewal, D., Mahr, D., de Ruyter, K., \& Wetzels, M. (2018). The Effect of Review Writing on Learning Engagement in Channel Partner Relationship Management. Journal of Marketing, 82(2), 6484. https://doi.org/10.1509/jm.15.0121

Document status and date:

Published: 01/03/2018

DOI:

10.1509/jm.15.0121

Document Version:

Publisher's PDF, also known as Version of record

Document license:

Taverne

Please check the document version of this publication:

- A submitted manuscript is the version of the article upon submission and before peer-review. There can be important differences between the submitted version and the official published version of record.

People interested in the research are advised to contact the author for the final version of the publication, or visit the DOI to the publisher's website.

- The final author version and the galley proof are versions of the publication after peer review.

- The final published version features the final layout of the paper including the volume, issue and page numbers.

Link to publication

\footnotetext{
General rights rights.

- You may freely distribute the URL identifying the publication in the public portal. please follow below link for the End User Agreement:

www.umlib.nl/taverne-license

Take down policy

If you believe that this document breaches copyright please contact us at:

repository@maastrichtuniversity.nl

providing details and we will investigate your claim.
}

Copyright and moral rights for the publications made accessible in the public portal are retained by the authors and/or other copyright owners and it is a condition of accessing publications that users recognise and abide by the legal requirements associated with these

- Users may download and print one copy of any publication from the public portal for the purpose of private study or research.

- You may not further distribute the material or use it for any profit-making activity or commercial gain

If the publication is distributed under the terms of Article $25 \mathrm{fa}$ of the Dutch Copyright Act, indicated by the "Taverne" license above, 


\section{The Effect of Review Writing on Learning Engagement in Channel Partner Relationship Management}

To develop the knowledge and skill sets of channel partner firms, manufacturers increasingly introduce learning programs as part of their relationship management strategies. However, the engagement of channel partners in these programs tends to be low. The current research, conducted in collaboration with a Fortune 100 information technology company, examines ways to strengthen learning engagement. In accordance with self-regulated learning theory, the authors propose and demonstrate that when channel partners write reviews of a learning module that they attended, beyond providing ratings, they are better able to reflect on the relevance of their learning experience and are further engaged in learning activities. The audience and focus of these written reviews determine the engagement of the channel partner sales personnel; therefore, review writing is a valuable, informal mechanism to motivate them. These effects are moderated by characteristics of both the channel partner (salesperson's learning orientation and identification with the manufacturer) and the relationship with the manufacturer (length and exclusivity).

Keywords: partner relationship management, self-regulated learning, feedback systems, review writing

Online Supplement. http://dx.doi.org/10.1509/jm.15.0121

$C^{2}$ hannel partners—-defined as independent intermediaries of a supplier's downstream networks that sell products to other channel members or end users (Hughes and Ahearne 2010) — often drive suppliers' bottom lines, accounting for as much as $65 \%$ of their total revenue (Accenture 2010). Recognizing the strategic importance of these resellers, many suppliers commit substantial resources to partner relationship management (PRM; Palmatier 2008; Palmatier, Dant, and Grewal 2007).

Such a strategy often prioritizes education, with the aim of helping the resellers and their employees gain a clearer understanding of the suppliers' offerings and build vital competencies

Elizabeth Aguirre is a postdoctoral researcher in marketing, Maastricht University, (email: e.aguirrelopez@maastrichtuniversity.nl). Dominik Mahr is Associate Professor of Marketing and Supply Chain Research, Maastricht University, and Adjunct Professor, University of Waikato (email: d.mahr@ maastrichtuniversity.nl). Ko de Ruyter is Professor of Marketing, Cass Business School, City University London (email: ko.de-ruyter.1@ city.ac.uk). Dhruv Grewal is Toyota Chair in E-Commerce and Electronic Business, Babson College (email: dgrewal@babson.edu). Jan Pelser is a postdoctoral researcher in marketing, Maastricht University (email: j.pelser@maastrichtuniversity.nl). Martin Wetzels is Professor of Marketing, Maastricht University, and Adjunct Professor, University of Waikato (email: m.wetzels@maastrichtuniversity.nl). This article is based on the first author's doctoral dissertation, and the first author collected and analyzed all data for the studies with the supervision of Dominik Mahr and Jan Pelser. The authors are grateful for the helpful comments of Anne Roggeveen, the data collection support of David Cox and Ryan Faithfull and the access to the proprietary data of the global Fortune 100 company. Michael Ahearne served as area editor for this article. that promote sales. The learning management systems that suppliers offer as part of a PRM strategy might include forums and virtual meeting rooms for knowledge exchange, collaborative learning opportunities, social networking, and peer support (Harmon et al. 2013). For example, IBM's "Know Your IBM" program and Partner World University host thousands of online learning modules for its channel partners, related to critical sales and technical skills. In addition, HP Enterprise recently announced plans to add a solutions and competency component to its Partner Ready program, to extend beyond product-focused offerings. It provides various training modules and resources to help develop channel partners' competencies (Haber 2016).

However, PRM programs often suffer from low participation rates and insufficient partner engagement (Hennessy, Powers, and Kirk 2012), such that providers seek effective solutions to the unique challenges of leveraging education as a strategic PRM activity in marketing channels. For any single supplier, it is difficult to motivate salespeople employed by channel partners to devote their time and effort voluntarily to self-directed learning about specific offerings; such salespeople likely receive PRM solicitations and educational offerings from many suppliers (Anderson, Lodish, and Weitz 1987; Hughes and Ahearne 2010). Although some employees might recognize the value of professional development (CSO Insights 2014; Ford et al. 1998) and find participation rewarding (Palmer, Lunceford, and Patton 2012), large segments remain unengaged (Hennessy, Powers, and Kirk 2012). Existing incentive structures that offer cash or soft benefits (e.g., preferred partner status) quickly become ineffective or even counterproductive (Gilliland and Kim 2014). 
In response, some innovative learning programs, such as Lenovo's Expert Achievers Program, a worldwide business partner portal, have added feedback systems to allow participants to rate their experiences and write reviews of the learning modules (Fiorletta 2012). Anecdotal evidence suggests that people reflect on their experiences more when they share information about them (The New York Times 2011). Substantive evidence provided by research on self-regulated learning affirms that when writing prompts elicit reflective thinking, the writers become more aware of their own learning processes (Jacobs and Paris 1987). With such self-reflective assessments, learners plan better, make more effective use of their cognitive resources (e.g., attention), and become more interested in gaining further knowledge (Hulleman and Harackiewicz 2009). Therefore, asking channel partners to write a review of a learning module may activate their reflections on developing their own ability and skills, thereby instigating and encouraging them to engage in more training.

In this sense, review writing is a communication process that makes the salesperson's reflection about his or her learning experience explicit. It comprises three constituent features: sender, recipient, and message. We anticipate influences of all three factors, because they determine the writer's allocation of metacognitive resources. The channel partner's sales personnel (i.e., sender or learner of the module) participates in the learning module and writes a review of it, so their characteristics, such as their willingness to improve, as manifested in their learning orientation (LO; Ford et al. 1998), should be influential. These writers might view the supplier firm or their peers (i.e., recipients) as the audience or beneficiary of the review. Accordingly, we assess whether the audience is similar (peers/ other resellers) or dissimilar (manufacturer/supplier) to the reviewer. The message element reflects the attention focus that the learner adopts in describing his or her experience with the learning module, such as broader versus more narrow focus of the review. Our analysis also includes channel-specific contingencies identified in prior marketing channels literature, such as the channel partner's identification with the supplier, relationship length, and the exclusivity of the relationship (i.e., if the channel partner has only one upstream supplier but the supplier has multiple channel partners).

Research on self-regulated learning theory (Zimmerman and Schunk 2001) has also demonstrated that people vary considerably in their ability to reflect on their experiences or recognize personal advancement (Ford et al. 1998). That is, the motivational force that results from writing a review may be stronger with some people but weaker among others. Furthermore, differences in the frames that prompt people to reflect on their experiences produce distinct outcomes (Sheldon, Dunning, and Ames 2014). Therefore, to assess whether review writing motivates subsequent training uptake by channel partners, we take this granular heterogeneity into careful account. We consider different types of reviews to determine how they drive learning engagement behaviors. A more elaborate review (e.g., written review), relative to a simple, overall rating (e.g., star rating), should trigger more reflective thinking. Furthermore, we probe the mechanism by which review writing affects behavioral engagement, such that we investigate how self-reflection leads people to realize the relevance of learning activities, which then affects their future behavior. Writing a review of a learning module (vs. providing a rating) likely triggers a reflexive realization of the relevance of the supplier-provided training to the reseller's sales performance, thereby functioning as a motivator of further learning engagement. We present the theoretical framework in Figure 1.

By investigating the concepts and relationships in this framework, we aim to make three main contributions to marketing channel literature. First, this study offers an initial examination of feedback systems as tools for engagement, in line with the shift toward relationship marketing in channel contexts (Palmatier 2008). We propose that channel partners' self-reflection on their learning experiences, triggered by feedback systems, influences their future engagement likelihood. This consideration goes beyond a traditional view of feedback as simple input that the manufacturer can use to improve the quality of its offerings (Golder, Mitra, and Moorman 2012; Voss et al. 2004). Because channel partners with low LO are less able to engage in reflection (Ford et al. 1998), we explore different forms of feedback systems to understand how they drive learning engagement behaviors by different channel partners.

Second, we draw on self-regulated learning theory (Zimmerman and Schunk 2001) and examine its boundary conditions to offer a more fine-grained view of when reviews of a learning experience promote effective engagement in learning programs. We consider two central features of self-reflective evaluations prompted by reviewing activities - the beneficiary (peers vs. manufacturer) and the perspective taken (broad vs. focused)and how they direct the focus of the reflection, such that they might enable effective metacognition that fosters appreciation for learning. To advance understanding of feedback systems specific to channel contexts, we further identify and analyze channel-specific contingencies related to the channel partners and their relationship with the supplier.

Third, we probe the underlying mechanism by which feedback writing affects engagement by investigating how self-reflection can help resellers increase their learning activities. We explore whether more subtle interventions, such as feedback writing, trigger similar outcomes. In a PRM context, we reveal whether feedback writing about a previous learning experience triggers channel partners to realize the relevance of that experience to their day-to-day business activities, which could increase their behaviors dedicated to learning activities in the future. That is, we identify new mechanisms to strengthen interorganizational relationships, beyond trust and commitment (Palmatier, Dant, and Grewal 2007).

\section{Theoretical Background}

Self-regulated learning strategies put PRM participants (learners) in control over cognitive processes, in that they monitor and reflect on their own knowledge (Zimmerman 2002). Selfevaluative reflection involves comparing one's own knowledge against goals or standards, so it makes people more aware of their competencies, learning progress, and thought processes (Somuncuoglu and Yildirim 1999). Recognition of these cognitive processes allows people to make regulatory decisions, such as where to allocate attention or cognitive resources, which can facilitate further learning and improve performance (Anseel, Lievens, and Schollaert 2009). Selfawareness helps people recognize their learning strengths and 


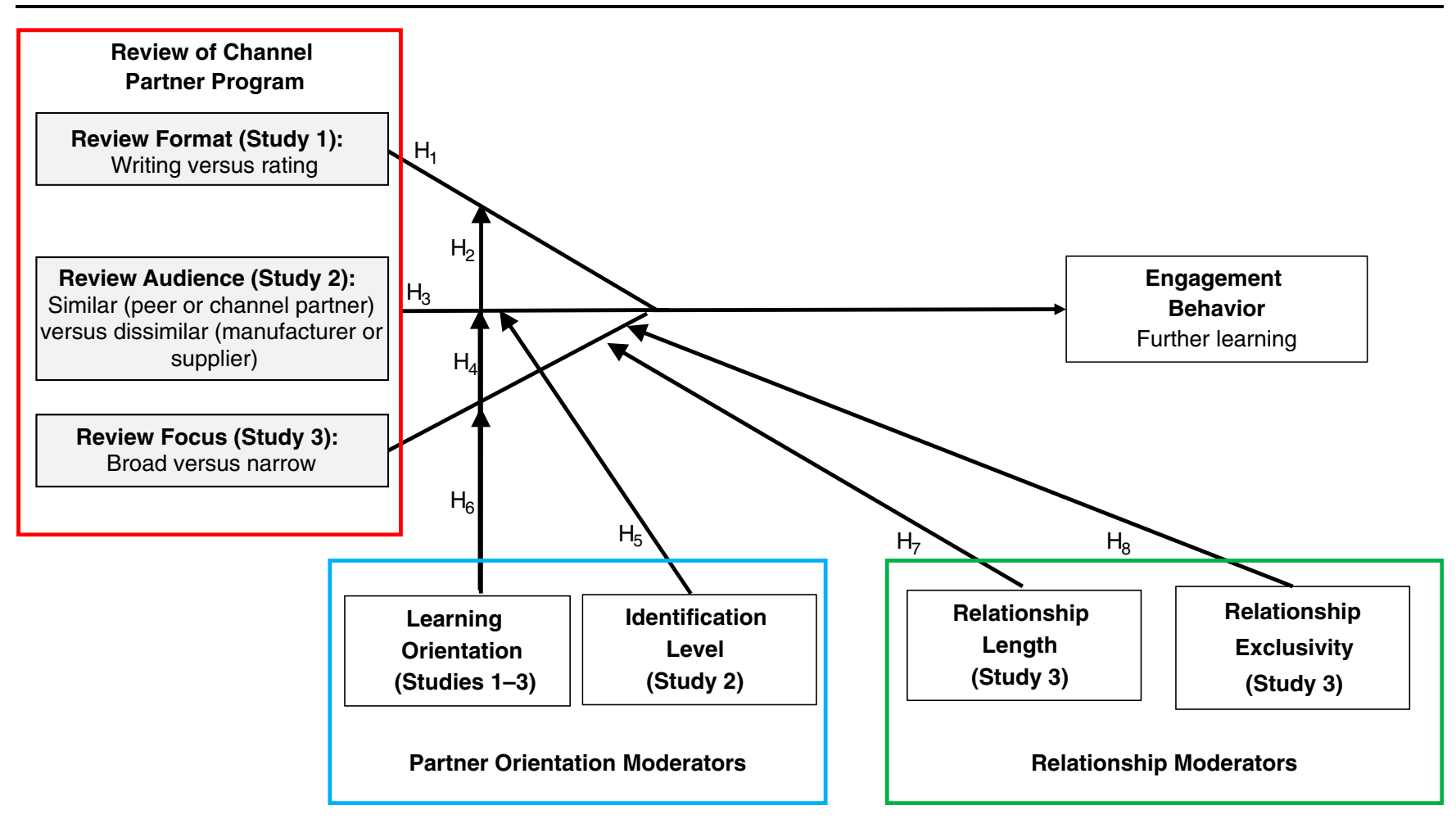

Notes: $H_{1}$ and $H_{2}$ are assessed in Study $1, H_{3}-H_{5}$ in Study 2, and $H_{6}-H_{8}$ in Study 3.

weaknesses, thereby motivating them to engage in activities that help them grow (Grant, Franklin, and Langford 2002; Sheldon, Dunning, and Ames 2014; Sitzmann and Ely 2010).

Self-reflective evaluation may be prompted by feedback systems, such as ratings or review writing, which require learners to assess their personal knowledge and skill acquisition. Both practices ask learners to make subjective assessments, but review writing is more elaborate, demanding that the learner explicate verbal representations of his or her thoughts and make associations among pieces of information. That is, review writing triggers self-reflection, which prompts the reviewer to elaborate on and gain a more precise understanding of her or his thoughts (Li, Liu, and Steckelberg 2010). Through this process, the learner can make sense of and interpret her or his experiences, which influences the way he or she thinks about them (Applebee 1984; Glogger et al. 2012; Klein 1999). Thus, compared with simply clicking a numerical rating or assigning some number of stars, writing a review should trigger metacognitive awareness that helps a learner obtain a deeper understanding of his or her learning experiences (Cho and MacArthur 2011; Klein 1999; Kuhrt and Farris 1990). In particular, as reviewers evaluate their experiences, they make associations between newly acquired and previously known information, then integrate them by finding patterns. The realization of the personal value of the learning experience in turn is critical for the reviewers' motivation to expend effort for further learning (Miller and Brickman 2004).

Accordingly, the process must involve learning that is personally relevant; relevant information is needed to motivate salespeople to engage in the effortful cognitive processing of information required to perform this metacognitive reflection (Zaichkowsky 1994). When information has greater personal relevance, a learner can perform better, because that relevance triggers him or her to synthesize information, recognize his or her strengths and weaknesses, and strive for an improved state of knowledge (Zaichkowsky 1994). This recognition also should influence behavior (Boud, Keogh, and Walker 1985), leading salespeople in marketing channels to pursue learning and performance improvements (Anseel, Lievens, and Schollaert 2009). For example, systematic after-action reviews conducted between trainers and trainees can stimulate organizational learning (Ellis and Davidi 2005; Villado and Arthur 2013). Through feedback functions, after-action reviews help organizational learners confirm or update their conceptual and metacognitive knowledge (Ellis and Davidi 2005). Despite these broader insights into the benefits of metacognition in organizational settings, insights into how to use it to motivate channel partner representatives to learn and work better in marketing channel relationships are limited.

Previous marketing studies addressing how to trigger channel partners' activity in channel relationships have identified manufacturer investments, such as tangible assets (e.g., equipment, IT systems, facilities; Kim, Cavusgil, and Calantone 2006), intangible assets (e.g., training, coordination support; Pelser et al. 2015), or monetary and nonmonetary incentives (Kashyap, Antia, and Frazier 2012) as potential solutions (for an overview, see Table 1). Yet channel-related activities, such as review writing, have not been addressed as potential tools to 


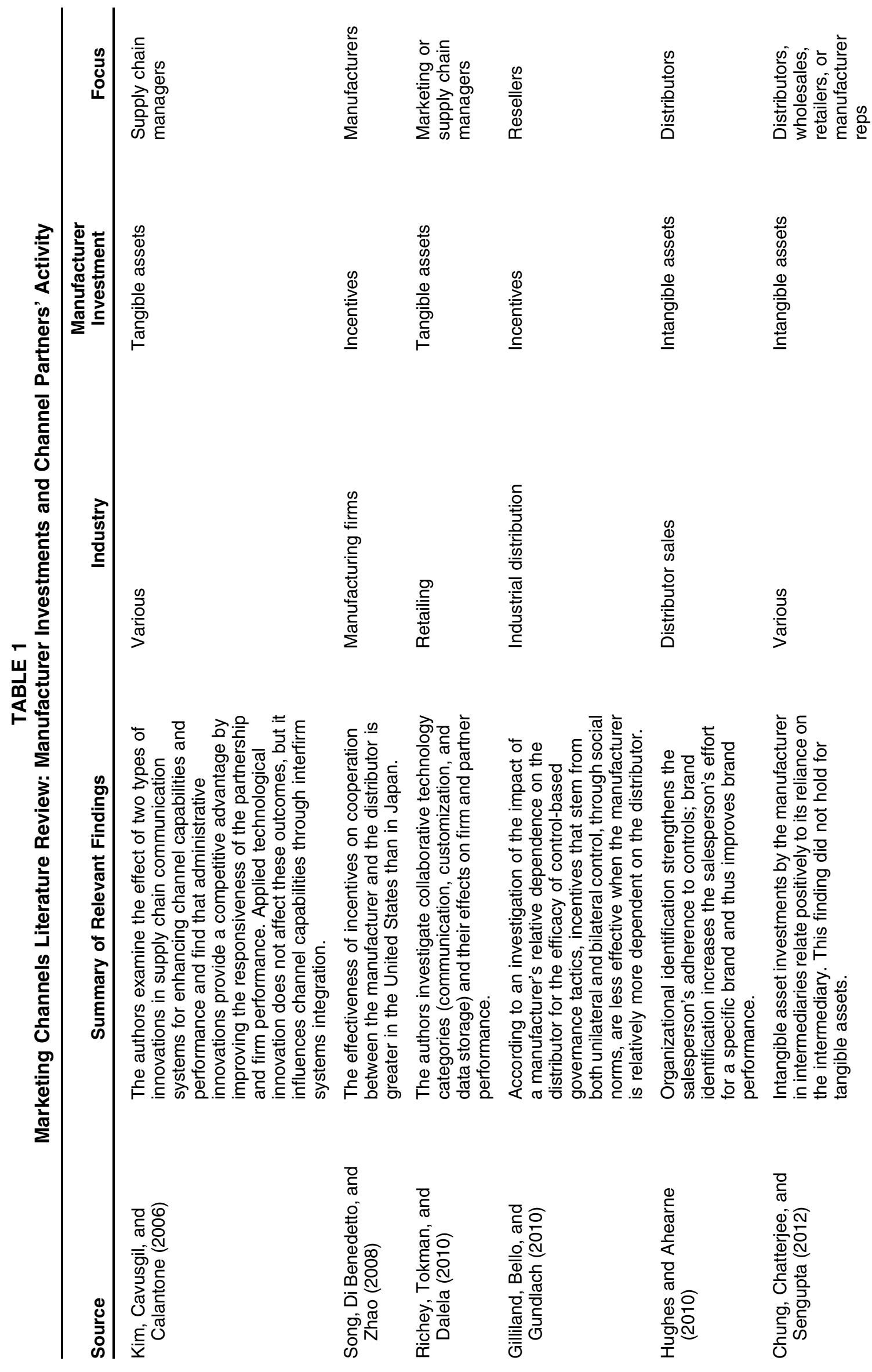




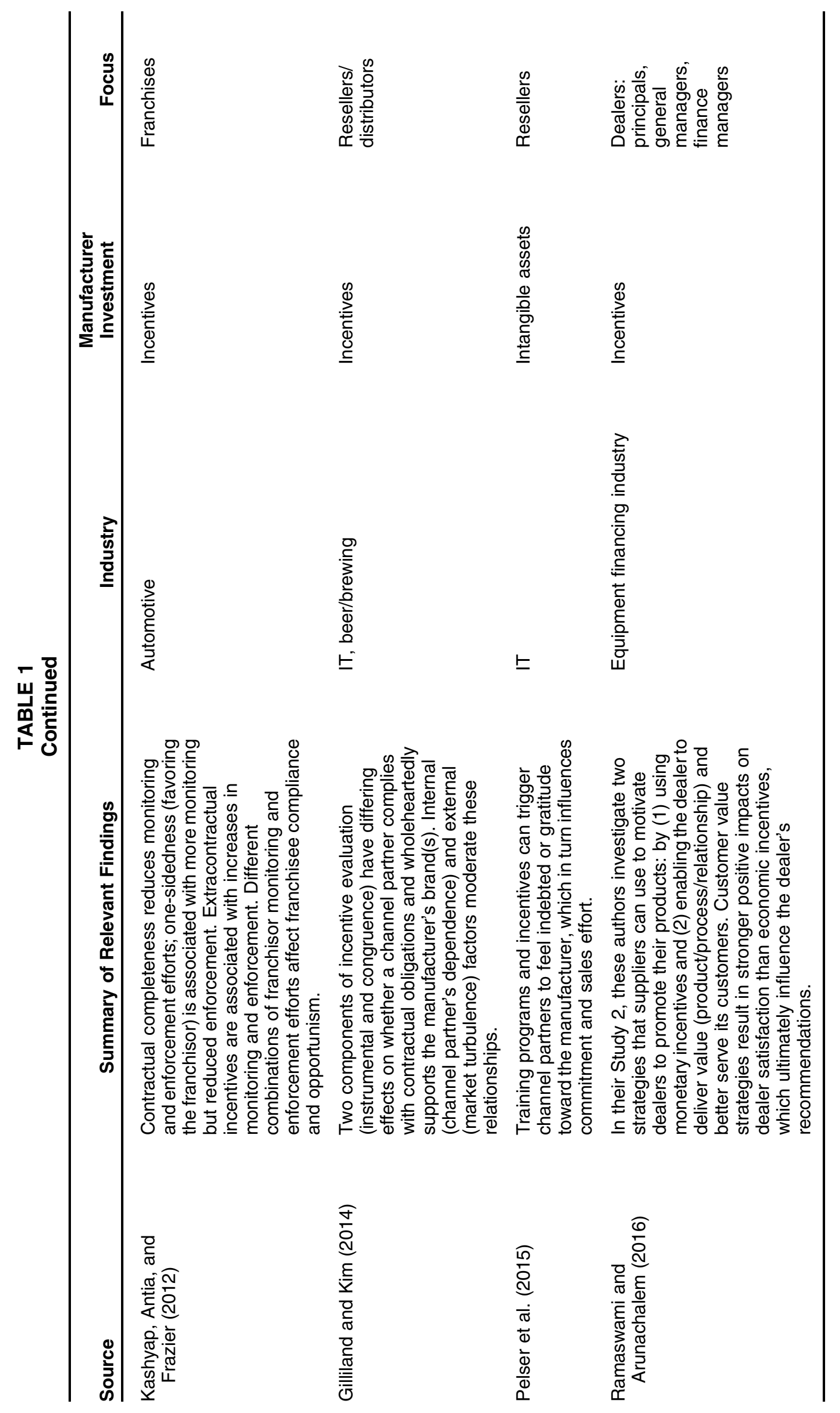


activate channel partner behaviors or enhance the learning engagement of these members of the channel. By studying the effects of the review writing activity, we aim to extend prior research that has identified learning opportunities as motivators, such that rather than the straightforward incentive, we consider how metacognitive efforts related to this incentive exert an impetus for further learning.

\section{Hypothesis Development}

\section{Effects of Review Writing on Learning Participation}

Feedback systems require participants to reflect on and assess their past experiences. Although all feedback systems exhibit this retrospective characteristic, they differ in the extent of deliberation required; verbatim reviews are more elaborate than numerical or star ratings. Ratings are simple and straightforward, such that they do not require cognitive elaboration or dedicated effort.

Unlike ratings, written reviews require the reviewer to reflect, more critically and extensively, on his or her experience by putting it down in writing, which can invoke metacognition (Magnifico 2010). As a reviewer engages in a metacognitive process, (s)he reflects on the experience and seeks to apply what (s)he has learned to other contexts (Boud, Keogh, and Walker 1985). This self-reflective evaluation of the learning experience thereby increases the relevance of the learning to the reviewer and may affect performance outcomes (Anseel, Lievens, and Schollaert 2009; Hulleman and Harackiewicz 2009). In effect, through writing and the ensuing self-regulated learning, a reviewer realizes the value of the knowledge gained, which should make him or her more likely to engage in future learning activities. Thus, review writing, as a metacognitive intervention, helps reviewers become more self-aware about what they have learned, increases learning engagement, and raises the likelihood of future learning (Sitzmann and Ely 2010).

In PRM specifically, review writing should activate the selfregulated learning that triggers channel partner salespeople to reflect on their learning experiences with the supplier-provided learning modules and relate these experiences to their day-today business activities. Because these learning modules are designed specifically to help resellers and their employees, the realization that the modules are relevant could motivate participation in additional learning programs.

$\mathrm{H}_{1}$ : Review writing activates channel partner sales employees to pursue further learning more than rating does.

\section{Moderating Influence of $L O$}

Salespeople must learn continuously and apply their acquired knowledge and skills to their work tasks (Sujan, Weitz, and Kumar 1994; Wang and Netemeyer 2002), so a strong LO is beneficial in both the short and long run (Harris, Mowen, and Brown 2005; Kohli, Shervani, and Challagalla 1998). It even can become manifest at the organizational level (Bell, Mengüç, and Widing 2010).

We posit that salespeople with lower LO might benefit more from review writing, because it helps them recognize the relevance of the learning programs for their professional development in ways that they would not have recognized otherwise. The prompted self-reflection then could pave the way to purposeful behavioral change (Grant, Franklin, and Langford 2002), including increased participation in learning activities. People with higher LO already display an inherent willingness to improve (Dweck 1986; Dweck and Leggett 1988) and recognize the benefits of learning modules, so they likely monitor their learning progress, regardless of whether they engage in review writing.

People with a lower LO are not innately driven to learn and have difficulty motivating themselves to exert the necessary effort to engage in metacognition (Ford et al. 1998). Thus, they may fail to gain a rich understanding of their own thoughts and personal progress in learning situations, and they may be reluctant to seek activities to improve and develop themselves (Sheldon, Dunning, and Ames 2014). Even though people with lower LO possess poorer innate metacognitive skills, it is possible to activate their metacognition through interventions that prompt reflection (Pintrich 2004; Schunk 2005; Veenman, Van Hout-Wolters, and Afflerbach 2006). Accordingly, we predict that for salespeople with lower LO, encouraging them to reflect on their learning by writing a review has a more salient and powerful effect than simply rating the training module.

$\mathrm{H}_{2}$ : Review writing (vs. rating) activates low-LO channel partner sales employees to pursue further learning but does not affect those with a high LO.

\section{Effects of Audience of the Written Review}

Reviewers typically have an audience in mind, which defines the purpose of their writing task (Magnifico 2010). The purpose relates closely to the beneficiary of the review, who might be similar or dissimilar to the reviewer. When reviewers consider an audience that is like themselves, they tend to assimilate their point of view into the review, in a process called social metacognition (Jost, Kruglanski, and Nelson 1998). A review provided for a similar other thus contains information that is personally relevant for the reviewer (Lerouge and Warlop 2006; Naylor, Lamberton, and Norton 2011), which is not the case for a dissimilar beneficiary.

If salespeople employed by channel partners review a learning module for their peers, they might write about the returns of their learning experience, such as how the content helps them complete daily work tasks (Miller and Brickman 2004). If salespeople, as learners and reviewers, are primed to think that similar partners will benefit from their reviews, they may engage in more metacognition, through self-reflection, which then should help them realize the relevance of the learning modules to their sales activities and motivate them to participate in additional learning programs. However, if they review them for the supplier (i.e., dissimilar other), they may not engage as effectively in this metacognitive process, such that they would have a harder time realizing the relevance of the learning modules and ultimately would be less motivated to participate in additional learning programs.

$\mathrm{H}_{3}$ : Review writing for an audience of peers (similar others) increases channel partner sales employees' pursuit of further learning more than review writing for a manufacturer (dissimilar others) audience. 


\section{Moderating Influences of Individual Differences}

Salespeople with high LO already engage in metacognition and may not benefit from further interventions $\left(\mathrm{H}_{2} ; \mathrm{Schmidt}\right.$ and Ford 2003), but those with low LO could benefit even more from writing for peers (i.e., similar others), which prompts them to probe their personal learning experiences more closely than does writing a review for the benefit of the manufacturer (i.e., dissimilar others). This greater stimulated reflection then should result in increased learning engagement (Sitzmann and Ely 2010).

$\mathrm{H}_{4}$ : Review writing for an audience of peers (similar others) increases the pursuit of future learning more among channel partner sales employees who have a low (vs. high) LO.

Moreover, channel partner employees identify with the upstream supplier to varying degrees (Hughes and Ahearne 2010). Identification with an organization implies a sense of connectedness and oneness with it (Mael and Ashforth 1992) because of perceived similarities with that group (Gammoh, Mallin, and Pullins 2014). This perception in turn fosters more intrinsic motivation and behaviors congruent with the organization's interests, reflecting an alignment of organizational and personal goals (Badrinarayanan and Laverie 2011; Hughes and Ahearne 2010). Such identification is common with employers, but it also might arise for other partners in a channel context. For example, a salesperson could describe her or his role as "a salesperson of Manufacturer X's product for Reseller Y." Such channel-based relationships do not require formal associations (Badrinarayanan and Laverie 2011), but they can lead to better job performance (Ahearne, Bhattacharya, and Gruen 2005) and prosocial citizenship behaviors (Bhattacharya and Sen 2003) as well as to the potential for conflict among the multigroup identities (Wieseke, Geigenmüller, and Kraus 2012).

If a channel partner's sales employees identify more strongly with the supplier, they focus on how their reviews can benefit that supplier. This attention to the manufacturer's goals is at odds with their natural assimilation with peers. That is, salespeople who identify closely with the supplier may have a harder time recognizing the value of the learning modules for their own and their peers' sales activities, so they could be less motivated to participate in additional learning programs. Formally, we posit:

$\mathrm{H}_{5}$ : The positive relationship between review writing for peers (vs. manufacturer) and the pursuit of future learning diminishes when the channel partner sales employees identify strongly with the manufacturer.

\section{Effects of the Message Focus of the Written Review}

The information included in a review may be broad, offering a bird's-eye view of a topic, or more narrow and detailed. In line with conceptual attention research, whether the message is broad or detailed likely influences how reviewers process the information (Friedman and Förster 2005). Messages in reviews might vary in their breadth of topics, with either a broad or detailed perspective (Applebee 1984). Broad conceptual activations trigger global processing of information and activate more concepts in memory, which should prompt people to think about the bigger picture. Writing a broad review also may trigger global processing, which activates associations in memory that do not relate directly to the topic at hand. A reviewer then would reflect on various issues, such as the fit of the learning module with other learning modules completed previously, rather than on the immediate, specific, personal experience with the learning module itself. Detailed concept activations instead induce local processing that triggers reviewers to focus on the specific subject matter (Förster 2012; Friedman and Förster 2005).

Construal-level theory further predicts that a good fit between the level of information stored (e.g., LO) and the information sought increases metacognitive ease (Kyung, Menon, and Trope 2014). ${ }^{1}$ People with a higher LO take a keen interest in their own personal development and devote time and cognitive effort to pursuing it, so they likely store each learning opportunity at a higher, abstract level, rather than the concrete, detailed level used by people with less expertise (Chase and Ericsson 1981; Ericsson and Kintsch 1995). Therefore, in response to a request for broad, abstract reviews, reviewers with higher LO, who already store the information at higher, abstract levels, can access it readily, whereas those with lower LO, who store more detailed information, may need to exert significant effort to sift through and connect the details gathered from various modules.

Low-LO reviewers writing a broad review likely struggle to identify the essential information or make sense of their learning experience, whereas reviewers with high LO who write a broad review can readily recognize the value of the module and its fit with their learning development. In contrast, if the prompt requests a focused review, channel partners with lower $\mathrm{LO}$ can rely on their local processing and write about concrete concepts immediately associated with their learning experience (Förster and Dannenberg 2010). Because they can easily access and focus on the relevant information, they likely engage in selfreflection, develop a greater understanding of the experience, and enjoy greater benefits of the focused review. Thus, the focus of the review should interact with LO as follows:

\section{$\mathrm{H}_{6}$ : Writing a broad (vs. narrow) review increases the pursuit of future learning more among reviewers with a high (vs. low) LO.}

In a marketing channel context, the focus of the review also should depend on the relationship between the partners. We consider two determinants of this relationship. First, a reseller and supplier might enter a one-time, discrete interaction or pursue an ongoing relational exchange (Palmatier, Dant, and Grewal 2007). Over time, channel actors tend to develop common expectations, adopt a long-term perspective, and focus on the broader business environment in which both parties operate (Palmatier, Dant, and Grewal 2007). We thus consider the moderating effect of relationship length, which is distinct from identification with the supplier, in that it pertains to the achievement of the reseller's goals within the channel, whereas identification centers solely on the supplier's goals. Accordingly, the consideration of the broader context that stems from

${ }^{1}$ Construal-level theory takes a matching perspective, and because a broad message focus and a narrow message focus match information storing at high and low LO levels, respectively, we do not predict a direct effect of message focus here. 
greater relationship length may affect the way in which the focus of the review influences the reviewer's future learning participation. Over time, having gained a broad understanding of the business context in which the channel relationship is embedded, the reviewer can relate his or her own strengths and weaknesses to this context and compare the value of the learning module with this extended frame of reference. Therefore,

$\mathrm{H}_{7}$ : The positive relationship between writing a broader review and the pursuit of future learning increases with channel relationship length.

Second, exclusivity in a channel relationship determines the power that the channel parties can exert, their motivations to work, and the channel's structures and performance (Antia, Zheng, and Frazier 2013; Gilliland and Kim 2014; Palmatier, Dant, and Grewal 2007). Reliance on one upstream supplier (vs. many) likely increases a reseller's in-depth attention to this specific relationship and this supplier's offerings (Gilliland and Kim 2014), but it also can increase the risk of channel conflicts (Koza and Dant 2007). Accordingly, many channel partners enter contractually exclusive agreements or preferred partnerships, which limits their exposure to the product portfolios of other suppliers. Conversely, nonexclusive channel partners, with their wider consideration sets, gain access to a wider range of information, which may lead to a broader focus on various learning experiences and partner relationships across the board. Therefore, nonexclusive channel partnerships may counteract the influence of taking a narrow focus in review writing and its self-reflective thinking.

$\mathrm{H}_{8}$ : The effect of review focus on the pursuit of future learning diminishes in exclusive (vs. nonexclusive) channel partner relationships.

\section{Effects of General Channel Features}

Several other variables influence channel partners' behaviors as well, beyond the hypothesized communication process variables. Therefore, we account for these general effects in our analyses. For example, sales experience, or the time a salesperson has functioned in this occupation, influences people's attitudes, perceptions, and sales performance (Cron and Slocum 1986). Several studies also note the influence of sales experience on empowerment, effort, and behavior (Ahearne, Mathieu, and Rapp 2005; Ahearne et al. 2010). Because sales experience might be confounded with the effects we predict, we include it as a control variable in all our studies.

We also acknowledge the different types of intermediaries within channels. Our sample comprises salespeople employed by resellers and distributors. Both types of intermediaries are independent of the manufacturer, but they differ in their commitments and investments to the relationship. For example, distributors tend to take more responsibility and ownership for products and likely provide a wider range of services to customers on behalf of the manufacturer. Such stronger commitments increase these channel members' reliance on the manufacturer (Chung, Chatterjee, and Sengupta 2012), which could have an influence on the hypothesized effects. We therefore control for the type of intermediary in all our studies.

Finally, reviews can be used to express affect or emotions (Ludwig et al. 2013). Reseller salespeople who write a positive review about their learning experience may be more likely to engage in future learning opportunities. Conversely, negative reviews may indicate potential for learner dropout. Thus, we consider the effects of review valence on further learning engagement.

These studies involve the global channel partners of one of the world's best-known technology brands and enable us to assess whether reviewing (vs. rating) a learning module increases the total number of subsequent learning modules completed by channel partners and to specify the potential moderating role of LO (Study 1). We also assess the effects of the audience (peer vs. supplier) and the moderating role of audience factors (LO and identification with the supplier) (Study 2). Finally, we examine the role of message focus (broad vs. narrow review) and the moderating effects of LO and two relationship factors (length and exclusivity of relationship) (Study 3).

\section{Research Setting}

The Fortune 100 manufacturer that cooperated with us on this research project makes its PRM central to its go-to-market strategy, because it regards its channel partners as extensions of its sales force. Through these resellers, it has been increasing its sales performance each year, and the partners are increasingly critical to its growth. To ensure continued success, learning programs within the PRM enable salespeople employed by the channel partners to operate effectively within the business ecosystem by providing them with resources to expand their capabilities and deliver value-added services.

The learning modules themselves reflect self-directed learning principles. Content appears in an interactive format, rather than in a traditional linear fashion, so that learners may focus on content that they deem important (e.g., conversation starters with clients). The sales-related content generally follows a three-lesson structure (i.e., value propositions and competitive positioning, in-depth offering information, and steps in the sales process). In addition, technology-related modules detail product specifications. Most of the modules pertain to specific offerings (e.g., cloud solutions), but some more generic modules on marketing, social media, analytics, financing, leasing, and pricing are available, too.

Learners usually need just under a half-hour to review the content in a module (though they may review more detailed content by clicking on hyperlinks). In principle, the modules are voluntary, and channel partners/resellers can complete as many modules as they like, such that there are no formal dependencies between modules. However, learning roadmaps offer some guidance, such as revealing which set of modules would enable participants to earn different forms of certification that are specific to the industry (e.g., analytics, cloud, security, storage, financing, social commerce). Approximately 35,000 employees of the supplier's resellers have successfully completed at least one certification track. Other guidelines also identify which modules pertain to a new product line or special theme (e.g., Flash systems boot camp, software-defined storage immersion).

To be counted, the learner must demonstrate comprehension by passing (scoring better than $80 \%$ ) a brief multiplechoice test at the end of each module. The system also unobtrusively records the number of page visits. Because the information must be current to be relevant, the supplier reviews all the modules it provides frequently and updates them when 
new products or updates are released. The PRM program also relaunches each year, with new content and (marketing) promotions.

All employees of resellers who participated in these studies were subscribed to the manufacturer's learning program, and we used unique channel partner identifications to ensure that no one participated twice. Prior to the studies, the supplier had not incorporated any feedback system. During the 2012-2013 period we study, it introduced 35 learning modules at different intervals, available to all its channel partners. In total, $61 \%$ of the manufacturer-provided modules were technical in focus, and $39 \%$ were sales focused.

The implicative value of this study also rests on the conventional premise that when salespeople engage in learning, it benefits the firm in the form of increased revenues. To establish the validity of this assumption in our PRM context, we examined the relationship between learning module uptake and revenues for 657 channel partners in one of the company's major product categories in the U.S. market across four quarters (2016 Q4 and 2017 Q1, Q2, and Q3). The significant Pearson correlation coefficient $(.21, p<.01$, two-tailed) between the number of modules completed and total revenue generated by these channel partners confirms this basic premise.

\section{Study 1: Writing Versus Rating Review}

With Study 1, we examine whether the method of providing feedback (i.e., writing about vs. rating the learning module) results in differences in channel partner sales employee (or reviewer) engagement over time $\left(\mathrm{H}_{1}\right)$. We also investigate whether this effect is moderated by the LO of the reseller employee $\left(\mathrm{H}_{2}\right)$. As a measure of engagement, we collected company data about the number of learning modules that each reviewer completed in the three months following his or her review or rating. That is, we asked all the learners in the data set to provide feedback about one learning module they had completed, either by writing a review or by offering a rating, and we observed how this action affected the number of modules they completed after three months.

\section{Design, Participants, and Procedure}

The design for Study 1 involved 88 participants who had subscribed to the learning program in the manufacturer's PRM; in return for their participation, they earned points in the manufacturer's incentive program. Participants either wrote a review (e.g., "In the space below, please provide feedback on the module. Please write at least 20 words about the module [the ideal length of feedback is approximately 75 words]") or provided a rating of a learning module (e.g., "Please rate the module on a scale of 1-10 [1-lowest; 10-highest]. Click on the pointer and slide it to the desired rating"). We excluded three participants from the analysis: one who could not write in the language of the study, another who was assigned to the review condition but did not write a review, and a third participant who did not take the study seriously (e.g., inputting an HTML address when asked to indicate age). Thus, the sample consisted of 85 participants $\left(\mathrm{M}_{\text {age }}=38.05\right.$ years, $\mathrm{SD}_{\text {age }}=7.91$ years; $\mathrm{M}_{\text {sales_experience }}=9.53$ years, $\mathrm{SD}_{\text {sales_experience }}=7.13$ years;
$8.20 \%$ women; $83.50 \%$ resellers; $30.60 \%$ worked exclusively with the manufacturer).

These participants considered a dropdown menu of modules offered by the program and selected one they had completed in the previous six months. This menu ensured that participants had a stable set of modules to select from, could easily recall those they had taken, and could recall the module name. Next, they provided a written review in the space provided or rated the module. Participants also completed an adapted, four-item version of a LO scale (Elliot and Church 1997; " I want to learn as much as possible from the modules that I take," "It is important for me to understand the content of each module as thoroughly as possible," "I always seek to have a broad and deep knowledge of each subject discussed in a module," and "I desire to completely master the material presented in each module I take"; $\alpha=.85 ; \mathrm{M}=6.06, \mathrm{SD}=.76$; $\min =4.00, \max =7.00)$, measured on a seven-point Likert scale ( 1 = "strongly disagree," and 7 = "strongly agree"). We averaged the four items, such that higher values indicated higher LO. We also incorporated two control variables for the model estimation, sales experience and user type (reseller or distributor), to control for individual differences that could affect the number of modules taken. Three months after the study, we collected behavioral information about the number of modules each participant had completed. During the study, participants took an average of $1.78(\mathrm{SD}=3.09)$ modules. Web Appendix 1 contains further descriptive information and the correlation tables.

\section{Results}

We estimated $\mathrm{H}_{1}$ using a zero-inflated Poisson (ZIP) model because the number of modules represented count data, and we found a considerable amount of zero values (50.6\%). A Vuong (1989) test confirmed the applicability of this model for our data. The dependent variable was the number of modules completed 90 days after the study; the independent variables were the review format (review $=1$; rating $=0$ ), $\mathrm{LO}$, and their interaction. Moreover, we included sales experience and user type as covariates.

As the results in Table 2 show, we uncover a significant main effect for the review format manipulation $(\beta=4.16$, incident rate ratio $[\mathrm{IRR}]=63.83, p=.02$ ), as predicted in $\mathrm{H}_{1}$. The IRR results (Long and Freese 2006) suggest that providing written reviews increases the number of modules subsequently completed, by a factor of 63.83 , with all other variables held constant. We find no significant effect of $\operatorname{LO}(\beta=.34$, IRR $=$ $1.41, p=.08)$, but the interaction between review format and LO is significant $(\beta=-.66, \mathrm{IRR}=.52, p=.03)$.

To explore the moderating influence of LO, we used the margins command in STATA12 (Williams 2012) to obtain estimates of the conditional marginal effects (or simple effects; Spiller et al. 2013) across values of LO, ranging from the observed minimum (4) to the observed maximum (7). Significant differences arise between the rating and writing formats for LO values between 4.37 and 5.61 (5\% significance). At higher values of LO, we find no significant differences between formats, in support of $\mathrm{H}_{2}$. Reviewers with lower $\mathrm{LO}$ are more likely to pursue additional modules after reviewing, rather than 
TABLE 2

Results of Studies 1-3

\begin{tabular}{|c|c|c|c|c|c|c|}
\hline \multicolumn{7}{|c|}{ A: Study $1\left(\mathrm{H}_{1}-\mathrm{H}_{2}\right)^{a}$} \\
\hline & \multicolumn{3}{|c|}{ Number of Modules } & & & \\
\hline & Coefficient & SE & IRR & & & \\
\hline $\begin{array}{l}\text { Constant } \\
\text { Feedback (rating }=0 \text {; reviewing }=1 \text { ) } \\
\text { LO } \\
\text { Feedback } \times \text { LO } \\
\text { Sales experience } \\
\text { User type (distributor }=0 \text {; reseller }=1 \text { ) } \\
\text { Log-likelihood } \\
\text { BIC } \\
\text { AIC }\end{array}$ & $\begin{array}{r}.04 \\
4.16 \\
.34 \\
-.66 \\
-.08 \\
-.46 \\
-157.39 \\
345.88 \\
328.78\end{array}$ & $\begin{array}{c}-1.38 \\
(1.83)^{\star} \\
-.20 \\
(.30)^{\star} \\
(.02)^{\star \star} \\
-.30\end{array}$ & $\begin{array}{r}1.04 \\
63.83 \\
1.41 \\
.52 \\
.93 \\
.63\end{array}$ & & & \\
\hline \multicolumn{7}{|c|}{ B: Study $2\left(\mathrm{H}_{3}-\mathrm{H}_{5}\right)^{b}$} \\
\hline \multicolumn{7}{|c|}{ Number of Modules } \\
\hline & \multicolumn{3}{|c|}{$\mathrm{H}_{3}-\mathrm{H}_{4}$} & \multicolumn{3}{|c|}{$\mathbf{H}_{5}$} \\
\hline & Coefficient & SE & IRR & Coefficient & SE & IRR \\
\hline $\begin{array}{l}\text { Constant } \\
\text { Purpose (manufacturer }=0 \text {; peers }=1 \text { ) } \\
\text { LO } \\
\text { Purpose } \times \text { LO } \\
\text { Sales experience } \\
\text { User type (distributor }=0 \text {; reseller }=1 \text { ) } \\
\text { Identification } \\
\text { Purpose } \times \text { Identification } \\
\text { Log-likelihood } \\
\text { BIC } \\
\text { AIC }\end{array}$ & $\begin{array}{r}-1.55 \\
6.20 \\
.37 \\
-.96 \\
.05 \\
.44\end{array}$ & $\begin{array}{l}-.99 \\
(1.38)^{\star \star} \\
(.15)^{\star \star} \\
(.23)^{\star \star} \\
(.01)^{\star \star} \\
(.17)^{\star \star}\end{array}$ & $\begin{array}{r}.21 \\
494.70 \\
1.45 \\
.38 \\
1.05 \\
1.55\end{array}$ & $\begin{array}{r}.04 \\
.44 \\
-.03 \\
-.24 \\
-161.04 \\
350.62 \\
336.07\end{array}$ & $\begin{array}{l}(.01)^{\star \star} \\
(.17)^{\star \star} \\
-.07 \\
(.09)^{\star \star}\end{array}$ & $\begin{array}{r}1.04 \\
1.55 \\
.98 \\
.79\end{array}$ \\
\hline
\end{tabular}

C: Study $3\left(\mathrm{H}_{6}-\mathrm{H}_{8}\right)^{c}$

\begin{tabular}{|c|c|c|c|c|c|c|c|c|c|}
\hline & \multicolumn{9}{|c|}{ Number of Modules } \\
\hline & \multicolumn{3}{|c|}{$\mathbf{H}_{6}$} & \multicolumn{3}{|c|}{$\mathbf{H}_{7}$} & \multicolumn{3}{|c|}{$\mathbf{H}_{8}$} \\
\hline & Coefficient & SE & IRR & Coefficient & SE & IRR & Coefficient & SE & IRR \\
\hline Constant & -1.57 & -1.81 & .21 & .34 & -.34 & 1.4 & .55 & -.33 & 1.73 \\
\hline Perspective (broad $=0 ;$ narrow $=1$ ) & 4.57 & $(2.10)^{*}$ & 96.26 & .03 & -.26 & 1.03 & -1.08 & $(.28)^{\star *}$ & .34 \\
\hline LO & .31 & -.28 & 1.37 & & & & & & \\
\hline Perspective $\times$ LO & -.83 & $(.34)^{\star}$ & .44 & & & & & & \\
\hline Sales experience & .03 & $(.01)^{\star *}$ & 1.03 & .02 & $(.01)^{\star}$ & 1.02 & .03 & $(.01)^{\star \star}$ & 1.03 \\
\hline User type $($ distributor $=0$; reseller $=1)$ & 1.24 & $(.31)^{\star \star}$ & 3.46 & 1.01 & $(.30)^{\star *}$ & 2.75 & 1.10 & $(.30)^{\star *}$ & 3.01 \\
\hline $\begin{array}{l}\text { Relationship exclusivity } \\
\quad(0=\text { nonexclusivity; } 1 \text { = exclusivity) }\end{array}$ & & & & & & & -.24 & -.27 & .79 \\
\hline Perspective $\times$ Channel dependence & & & & & & & 1.27 & $(.43)^{\star \star}$ & 3.57 \\
\hline Relationship length & & & & .03 & $(.02)^{\star}$ & 1.04 & & & \\
\hline Perspective $\times$ Relationship length & & & & -0.06 & $(.02)^{\star \star}$ & .94 & & & \\
\hline Log-likelihood & -126.84 & & & -127.02 & & & -125.08 & & \\
\hline $\mathrm{BIC}$ & 282.09 & & & 282.46 & & & 278.59 & & \\
\hline AIC & 267.67 & & & 268.04 & & & 264.17 & & \\
\hline
\end{tabular}

${ }^{*} p<.05$.

${ }^{\star \star} p<.01$.

aN $=85$ (nonzero $=42 ;$ zero $=43$ ).

bN $=59$ (nonzero $=34$; zero $=25$ ).

$\mathrm{cN}=58$ (nonzero $=32$; zero $=26$ ).

Notes: $\mathrm{BIC}=$ Bayesian information criterion; $\mathrm{AIC}=$ Akaike information criterion. Results are unchanged when we exclude the sales experience control variable (the interaction Z-value goes from 2.96 to 2.92 ). 
rating, a learning module, whereas at higher levels of LO, we find no significant differences between the two formats (Figure 2). Web Appendix 2 offers a comparison of the results when we use the number of modules completed within 30 days as the dependent variable; the results are substantively the same, with coefficients that are similar in their direction and significance.

\section{Discussion}

Firms invest substantially in developing learning programs to encourage employees of their channel partners to participate; increase their skills and product knowledge; and, thus, ideally achieve more sales. Study 1 lends support to $\mathrm{H}_{1}$ by revealing a positive main effect of review writing (vs. rating), which suggests that writing about one's own learning experience can lead to an increase in the number of modules taken. In addition, we find support for $\mathrm{H}_{2}$, such that writing reviews of a learning module can drive resellers who are less motivated learners to complete more modules during the subsequent three-month period than asking them to provide ratings. We explain this finding by positing that the review-writing process activates metacognitive thinking, which triggers participants with lower LO to evaluate their learning experience. However, writing reviews does not affect reviewers with higher LO, potentially due to ceiling effects. With a posttest, we investigate the underlying mechanism.

\section{Posttest}

The posttest involves 100 participants $\left(\mathrm{M}_{\mathrm{age}}=33.2\right.$ years; $28 \%$ women), gathered from Amazon Mechanical Turk. Before the study, a filtering question checked the eligibility of these respondents - namely, that they had performed a sales function at work within the previous seven years. In welcoming those who qualified for the study, an introduction noted that they would be tasked with evaluating a training program for sales representatives. Nine participants $(9 \%)$ were excluded, for various reasons: two could not write in English, two did not find the scenario believable, three indicated they had previously seen

\section{FIGURE 2 \\ Study 1: Interaction Between Feedback Manipulation and LO}

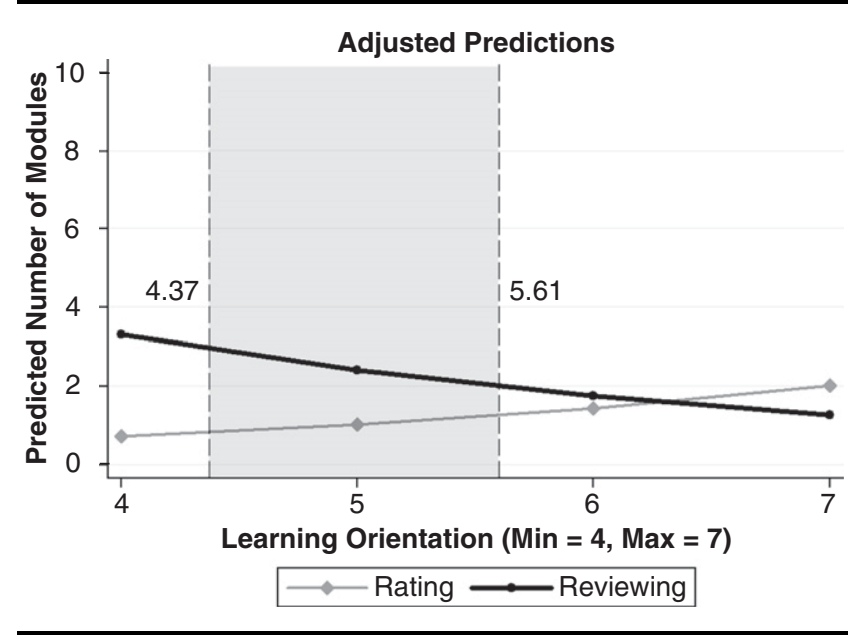

the video, and two noted that they did not pay attention to the video. The 91 remaining participants were instructed to imagine themselves as sales representatives of a fictitious company, MV Europe (Scheer and Stern 1992). Specifically, the instructions read:

Please read the following text carefully. As you read, imagine that you are in the following situation: You are a sales representative for MV Europe. MV Europe offers a full range of analytical tools and provides support and training to help get clients' analytical projects up and running. MV Europe has decades of project experience across analytical platforms including Alteryx, Lavastorm, and Rapid Minder, as well as with their core business products SAS and IBM SPSS. It is your responsibility to acquire new clients and close sales deals. As one of MV Europe's business partners, IBM offers you voluntary online educational modules to assist you with building your skills and knowledge of IBM's products and solutions portfolio, to make you an even more essential resource for your clients.

A recent set of modules that has been developed in collaboration with the Aberdeen Group is a series of four sales enablement modules. On the following page, you will be exposed to a snippet of one of these modules, entitled "Social Selling: Unleashing the Power of Social Media on B2B Sales Enablement." Please watch the snippet of the module carefully from the perspective of a sales representative for MV Europe. Afterwards, you will be asked to provide feedback about the module. Please put on your headphones now. If you are ready to continue, please click on the arrow button below.

Next, the participants watched a snippet (i.e., last 4 minutes) of a 14-minute video about the importance of social media in business-to-business sales. This snippet summarized the issues discussed in the full-length video. After viewing the video, the participants were randomly assigned to a feedback manipulation, to either review or rate the video, as in Study 1. Because they watched only a snippet, we asked participants whether they were interested in watching the rest of the 14-minute video, which provides the dependent variable to test learning engagement. For the mediator, we assessed relevance using a three-item scale ( $\alpha=.85, \mathrm{M}=5.81, \mathrm{SD}=.95)$ : "I believe that this online learning module offers valuable insights," "How relevant do you feel this online learning module is to your performance as a sales representative of MV Europe?" and "How connected did you feel this type of training module was to help you as a sales representative of MV Europe do your job better?" (Drewery, Pretti, and Barclay 2016).

To test the effect of the review format on interest as the dependent variable, through the mediation of relevance, we used PROCESS Model 4 (Hayes 2013). The mean indirect effect in the bootstrap analysis (bootstraps $=5,000$ ) is positive and significant $(\mathrm{a} \times \mathrm{b}=.23)$, and the $95 \%$ confidence interval does not include $0(.08, .44)$. In the indirect path, reviewing (vs. rating) increases relevance ( $\mathrm{a}=.24, \mathrm{~b}=1.01$ ), so holding the manipulation constant, a unit increase in relevance increases learning engagement. The direct effect of $c(.09)$ is not significant $(p=.491)$, in support of full or indirect-only mediation (Zhao, Lynch, and Chen 2010). That is, writing reviews can trigger metacognitive thinking by prompting participants to reflect on the relevance of the learning to their own experiences. In realizing the relevance of the learning experience, 
participants become more motivated to engage in further learning opportunities. Study 2 investigates how the audience of a review might affect further learning.

\section{Study 2: Audience of the Review: Peers Versus Manufacturer}

When the audience for the review is perceived as similar (i.e., peers or other resellers), it likely activates self-reflection because the reviewer assumes that his or her thoughts and preferences are in line with those of this audience (Lerouge and Warlop 2006), which is not the case when the audience is perceived as dissimilar. Therefore, prompting participants to write a review for a similar other (e.g., peers) rather than a dissimilar other (e.g., manufacturer) may induce metacognition, which could encourage their participation in new modules $\left(\mathrm{H}_{3}\right)$. Channel partners with lower LO could benefit from the self-focus that such writing provides, which could also translate into increased participation $\left(\mathrm{H}_{4}\right)$. Similarly, channel partners with lower identification with the supplier could benefit from the self-focus that such writing provides, which could translate into increased participation $\left(\mathrm{H}_{5}\right)$.

\section{Design, Participants, and Procedure}

The 64 participants received points from the manufacturer's incentive program. They also wrote reviews, for the benefit of either their peers (e.g., "In the space below, please provide feedback on the module. Your feedback will help improve the quality of the learning modules for other [program name] members. Please write at least 20 words about the module [the ideal length of feedback is approximately 75 words]") or the manufacturer that hosted the learning program (e.g., "In the space below, please provide feedback on the module. Your feedback will help [manufacturer] improve the quality of their learning modules. Please write at least 20 words about the module [the ideal length of feedback is approximately 75 words]"). Five participants were removed from the analysis (7.8\%): one who wrote incomprehensible gibberish, two identical entries, suggesting the same person participated in the study twice, and two others who simply cut and pasted the description of the module into their review. The remaining 59 entries entered our analysis $\left(\mathrm{M}_{\mathrm{age}}=39.10\right.$ years, $\mathrm{SD}_{\mathrm{age}}=8.85$ years; $\mathrm{M}_{\text {sales_experience }}=10.61$ years, $\mathrm{SD}_{\text {sales_experience }}=7.01$ years; $18.60 \%$ women; $67.80 \%$ resellers; $35.60 \%$ worked exclusively with the manufacturer).

Participants also completed the four-item LO scale $(\alpha=.89$; $\mathrm{M}=5.87, \mathrm{SD}=.88 ; \min =3.00, \max =7.00)$. To assess identification with the manufacturer, we use an adapted version of the Inclusion of Other in Self scale (Aron, Aron, and Smollan 1992), which consists of two circles that vary in their degree of overlap. Participants then must "assume that in each pair of circles in the scale, one circle represents you, while the other represents [manufacturer]. Please select the pair of circles that most accurately represents how close you feel to [manufacturer]." Sales experience and user type are covariates, and we again collected behavioral information after three months. During the study, participants took an average of $3.34(\mathrm{SD}=5.57)$ modules.

\section{Results}

Audience $\times L O$. We estimate a ZIP model, confirmed as appropriate by a Vuong (1989) test. The dependent variable is the number of modules completed 90 days after the manipulation; the independent variables are the audience manipulation (peers $=1$; manufacturer $=0$ ), LO, and their interaction. Sales experience and user type serve as covariates.

The results in Table 2 provide support for $\mathrm{H}_{3}$, such that writing for the benefit of peers increases the number of modules that channel partners take in the subsequent three-month period ( $\beta=6.20, \mathrm{IRR}=494.71, p<.01)$, compared with writing for the supplier. Moreover, LO affects this measure, such that higher LO corresponds to more modules taken $(\beta=.37$, IRR $=1.45$, $p=.01)$. As we predicted in $\mathrm{H}_{4}$, the interaction between the audience manipulation and LO is significant $(\beta=-.96, \mathrm{IRR}=$ $.38, p<.01)$ : low-LO participants who write for peers are more likely than their counterparts who write for the manufacturer to complete more modules, but this difference does not arise among participants with high LO.

We also use the margins command in STATA12 (Williams 2012) to obtain estimates of the conditional marginal effects (Spiller et al. 2013) at LO values ranging from the observed minimum (3) to the observed maximum (7). Significant differences arise in the audience manipulation for values of LO ranging from 3.26 to 6.12 (5\% significance). At higher values of LO, we find no significant differences across conditions, in support of $\mathrm{H}_{4}$. Participants with lower LO pursue more additional modules after providing a written review for the benefit of similar others (peers) than if they write for dissimilar others (manufacturer), whereas those with higher levels of LO show no significant differences (Figure 3).

Supplemental mediation analysis. To confirm that writing reviews for similar others triggers the reviewer to reflect on the relevance of the learning module, two independent coders with professional business experience read the randomized reviews and assessed the relevance of the module to the author of the review on a five-point scale ( 1 = "not at all relevant," and $5=$ "very highly relevant"), similar to the procedure in Krishnamurthy and Sivaraman (2002). Their intercoder agreement revealed a Krippendorff's alpha value of .82 (above the critical threshold of .80). Under the supervision of one of the authors, the coders discussed any disagreements until they reached consensus $(\mathrm{M}=2.25, \mathrm{SD}=1.31)$.

To understand whether relevance drives the effects, we accordingly conducted a test of mediated moderation, following the procedure recommended by Muller, Judd, and Yzerbyt (2005), in which we estimate three regressions. First, we assess the moderation of the overall treatment effect with a ZIP model that features the number of modules as the dependent variable and the audience manipulation, LO, and their interaction as independent variables, as well as sales experience and user types as covariates. We find consistent evidence for the predicted interaction between the audience manipulation and LO on the number of modules taken $(\beta=-.96$, IRR $=.38, p<.01)$. Second, we run a linear regression model that contains relevance as the dependent variable and the same independent variables, interaction, and covariates to investigate the treatment effect on this mediator. The effect of the audience manipulation 
FIGURE 3

Study 2: Purpose Interactions and Effects on the Number of Modules
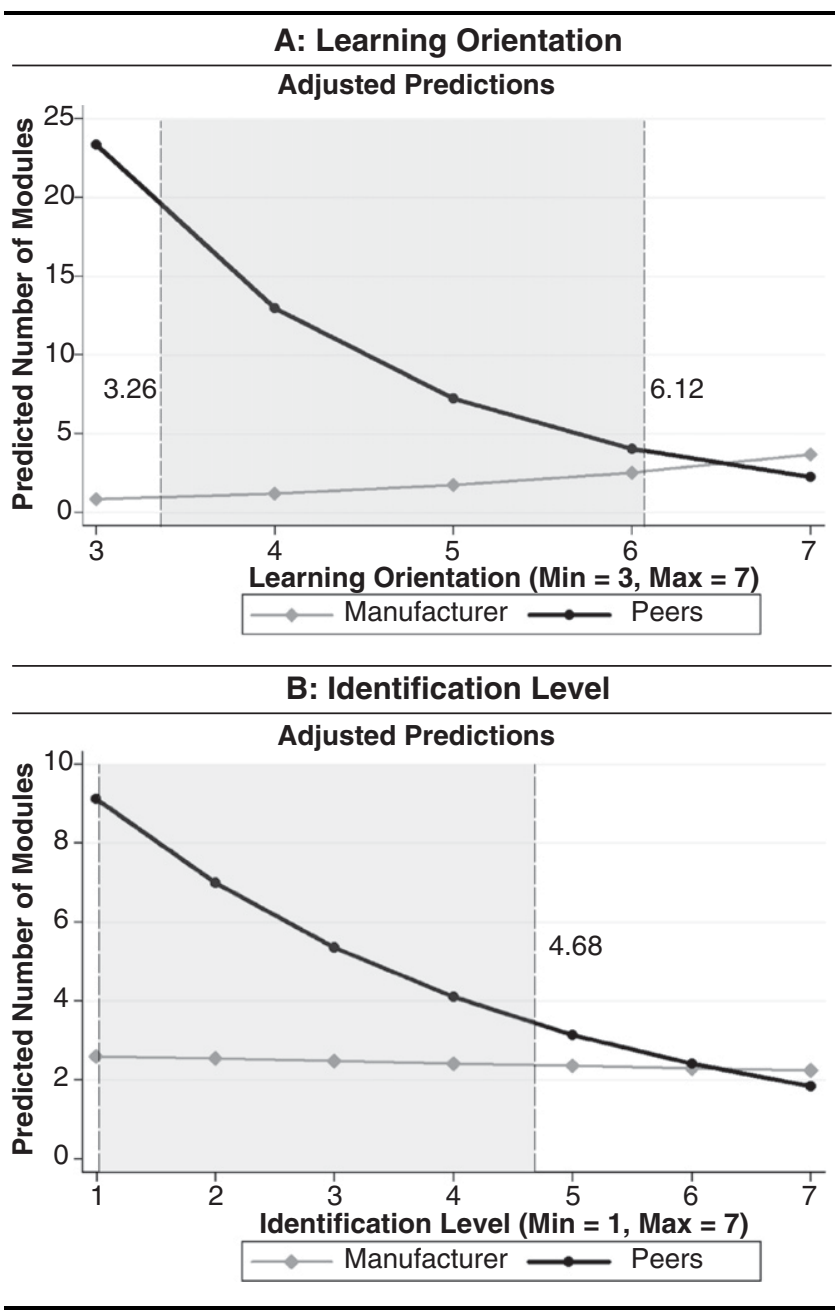

on relevance is moderated by $\mathrm{LO}(\beta=-1.28, p=.01)$. Third, we estimate a final ZIP model that includes the relevance mediator and its interaction with LO in the model from the first step. The findings reveal a significant effect of relevance on the number of modules $(\beta=-2.83, \mathrm{IRR}=.06, p<.01)$. The residual direct effect of the audience manipulation on the number of modules also is less moderated by $\mathrm{LO}$ after we control for relevance and its interaction with LO $(\beta=-1.03$, IRR $=.36, p<.01)$, as indicated by the minor yet significant decrease in IRR from .38 in the first step to .36 . Thus, relevance mediates the impact of writing for a similar (vs. dissimilar) audience and LO on the number of modules completed. We also test for the effect of alternative mechanisms, such as feelings of identification and ownership, but find no significant treatment effects.

Audience $\times$ Identification with manufacturer. With another ZIP model, we assess the effect of identification with the manufacturer. The main effect of identification is not significant $(\beta=-.03, \operatorname{IRR}=.98, p=.707)$, but its interaction with the audience manipulation is ( $\beta=-.24$, IRR $=.79, p<.01)$. Using the margins command of STATA12, we obtain estimates of the conditional marginal effects at different identification values. Significant differences appear in the audience manipulation for values of identification below 4.68 (5\% significance); no significant differences emerge for values of 4.68 or above. Therefore, the less the participant identifies with the manufacturer, the greater the difference of the effect invoked by writing for similar versus dissimilar audiences. In support of $\mathrm{H}_{5}$, the positive relationship between review writing for similar (vs. dissimilar) others and the reviewer's pursuit of future learning weakens when (s)he identifies strongly with the dissimilar other.

\section{Discussion}

The findings related to $\mathrm{H}_{3}$ and $\mathrm{H}_{4}$ are in line with the concept of social metacognition, such that reviewers with lower LO use their self-knowledge to stand in for the thoughts of others who are similar to them (i.e., peers). They share their personal experiences in their reviews, which helps them make sense of their learning experiences and realize the relevance of what they have learned for their day-to-day activities, thereby leading to greater future engagement in learning modules. But if they identify with dissimilar others (i.e., the manufacturer), the positive effect of review writing on this form of engagement is disrupted, as we predicted in $\mathrm{H}_{5}$.

By considering the audience for a review, we clarify how writing a review can lead reviewers to complete additional learning modules. Not all review writing effectively enhances engagement; only that which helps the participant focus on self-relevant information does so. We offer evidence that focusing on self-relevant information triggers reviewers to realize the relevance of the learning module for their work activities in the channel. Study 3 explores the message itself, according to its broad versus narrow focus.

\section{Study 3: Review Focus: Broad Versus Narrow}

The focus of the review might be broad or detailed, such that it relates to global or local processing styles, respectively. The activation of global processes could trigger more associations in memory that are not directly related to the reviewer's learning experience, which may prevent his or her realization of the relevance of the learning module to day-to-day channel activities. A broad focus also implies accounting for more information, which might overwhelm people with low $\mathrm{LO}$ and make it difficult for them to retrieve relevant information related to their learning experience. In contrast, we expect greater participation among channel partners with lower $\mathrm{LO}$ who provide a narrow-focused review $\left(\mathrm{H}_{6}\right)$. When the channel relationship is longer $\left(\mathrm{H}_{7}\right)$ and involves exclusive contractual arrangements between the reseller and supplier $\left(\mathrm{H}_{8}\right)$, the impact of the broader review focus also should increase future engagement behavior.

\section{Design, Participants, and Procedure}

The 65 participants received points from the manufacturer's incentive program. They were instructed to write either a broad review about how the module fit within their overall learning program (e.g., "In the space below, please provide feedback on how the module fits with your overall learning program within 
[program name]. Please write at least 20 words about the module [the ideal length of feedback is approximately 75 words]") or a narrow review of the module itself (e.g., "In the space below, please provide detailed feedback on the module [e.g., helpfulness, difficulty level, comprehensiveness]. Please write at least 20 words about the module [the ideal length of feedback is approximately 75 words]"). We excluded seven participants $(10.80 \%)$, because one wrote no reviews, another indicated that he had 100 years of sales experience, one indicated that he could not write in the language of the study, two had incomplete entries, and two simply cut and pasted the description of the module into their review. Thus, the sample contained 58 participants $\left(\mathrm{M}_{\mathrm{age}}=39.91\right.$ years, $\mathrm{SD}_{\text {age }}=10.36$ years; $\mathrm{M}_{\text {sales_experience }}=10.64$ years, $\mathrm{SD}_{\text {sales_experience }}=9.47$ years; $20.70 \%$ women; $77.60 \%$ resellers; $41.40 \%$ worked exclusively with the manufacturer).

The procedure was similar to that of Studies 1 and 2 . Participants selected a module they had completed from a dropdown menu, then provided a written review in the space provided. They also completed the four-item LO scale $(\alpha=.91$; $\mathrm{M}=6.06, \mathrm{SD}=.79 ; \min =3.50, \max =7.00)$, indicated whether they sold products exclusively for the manufacturer (as a measure of exclusivity), and provided the length of the relationship with the supplier in years. We use their sales experience and user type (distributor or reseller) as covariates. Three months after the study, we collected the number of modules each participant completed. During the study, they took an average of $2.60(\mathrm{SD}=4.20)$ modules.

\section{Results}

Focus $\times$ LO. A ZIP model again is appropriate (Vuong 1989). Table 2 contains the model estimates: the focus manipulation $(1=$ narrow review; $0=$ broad review $), L O$, and their interactions, as well as sales experience and user type as covariates. The focus manipulation has a significant main effect ( $\beta=4.57, \mathrm{IRR}=96.26, p=.03), \mathrm{LO}$ does not affect the number of modules $(\beta=.31$, IRR $=1.37, p=.26)$, and the interaction between review focus and LO is significant $(\beta=-.83$, IRR $=$ $.44, p=.02$ ), in support of $\mathrm{H}_{6}$.

The margins command in STATA12 (Williams 2012) again provides the estimates of the conditional marginal effects (Spiller et al. 2013) across the observed minimum (3.5) and maximum (7) values of LO. We find significant differences for lower LO values, ranging between 3.50 and 4.10 (10\% significance), such that reviewers with lower LO pursue additional modules after providing a narrowly focused review, rather than a broad one, unlike learners with higher levels of LO. Furthermore, we identify significant differences between the broad and narrow focus manipulations for higher $\mathrm{LO}$ values, ranging from 5.94 to 7 , at a $5 \%$ significance level. Here, higher-LO reviewers who provide broad reviews are more likely to pursue additional modules than if they write a detailed review (Figure 4). These results highlight the importance of the joint effects of the focus of the review and LO.

Mediation analysis. Following a procedure similar to that for Study 2, independent coders rated the relevance of the reviews (Krippendorff's $\alpha=.94$ ). First, we find evidence of the predicted interaction between the focus manipulation and $\mathrm{LO}$ on the number of modules taken $(\beta=-.83$, IRR $=.44, p=.02)$.
FIGURE 4

Study 3: Perspective Interactions and Effects on Number of Modules
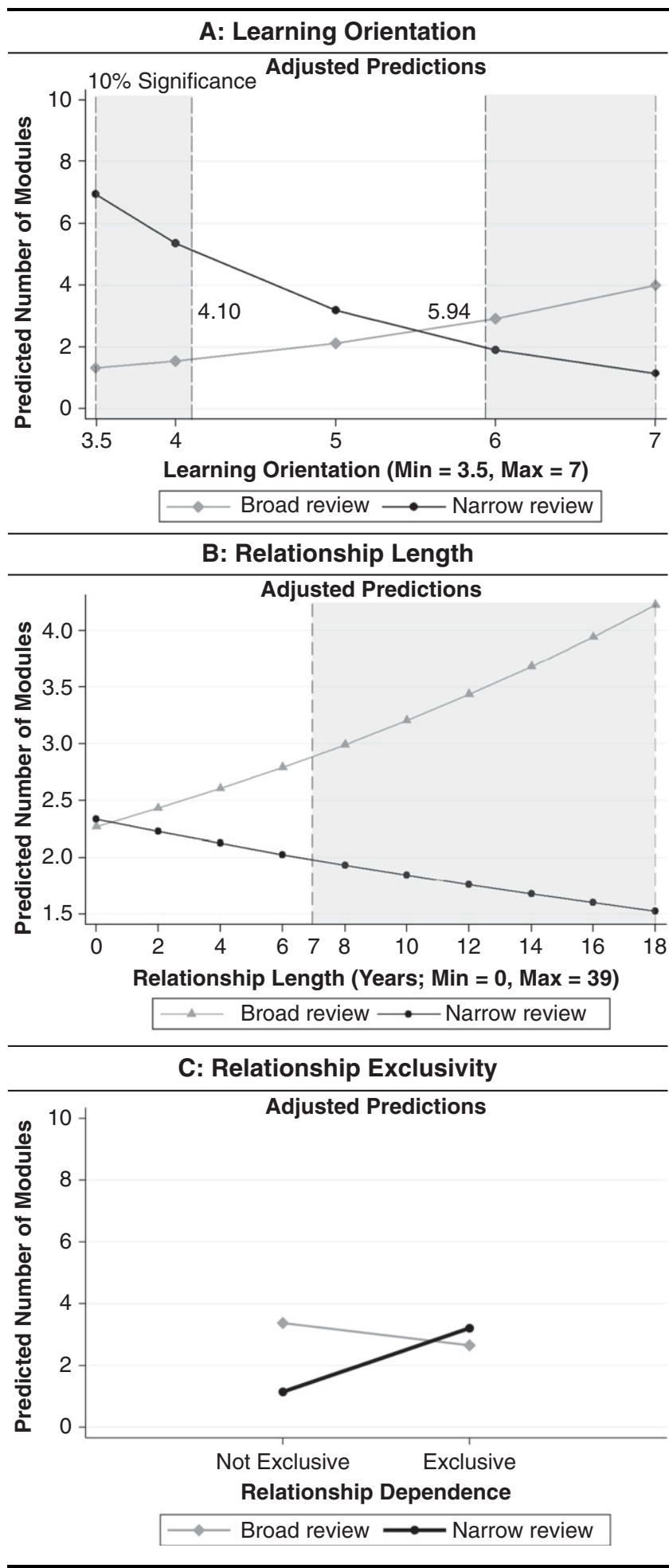

Second, a linear regression model contains relevance as the dependent variable, and the rest of the variables remain the same. The effect of the focus manipulation on relevance is moderated by LO ( $\beta=-.86, p=.06)$. Third, a final ZIP model 
includes relevance and its interaction with LO from the first model and reveals a significant effect of relevance on the number of modules taken $(\beta=-1.86, \mathrm{IRR}=.16, p=.04)$. The residual direct effect of the focus manipulation on the number of modules is less moderated by $\mathrm{LO}$ when we control for relevance and its interaction with LO $(\beta=-1.06, \operatorname{IRR}=.34, p<.01$; i.e., IRR decreases from .44 in the first step to .34).

Focus $\times$ Relationship length. To test $\mathrm{H}_{7}$, we investigate the moderating effect of relationship length using another ZIP model. We find a significant interaction between the focus manipulation and a longer relationship, which implies greater sales experience with the supplier's products $(\beta=-.06, p<.01$, IRR $=.94)$ after the channel relationship has lasted for at least seven years (5\% significance). In support of $\mathrm{H}_{7}$, the impact of review type on the reviewer's pursuit of future learning increases with the length of the channel relationship.

Focus $\times$ Relationship exclusivity. With another ZIP model, we assess the influence of relationship exclusivity, as indicated by the presence or absence of an exclusivity agreement between the reseller and the supplier. The main effect of exclusivity is not significant $(\beta=-.24, \operatorname{IRR}=.79, p=.372)$, but its interaction with the review focus manipulation is $(\beta=1.27$, $\operatorname{IRR}=3.57, p<.01)$. When reviewers are employed by firms that do not have exclusive relationships with the supplier, the difference between writing a broad or a narrow review is significant (dy/dx $=-2.23, \mathrm{z}=-3.23, p=.001)$. If such exclusive relationships exist though, this difference is not significant $(\mathrm{dy} / \mathrm{dx}$ $=.56, \mathrm{z}=.69, p=.489$ ). These findings support $\mathrm{H}_{8}$.

The support for $\mathrm{H}_{7}$ and $\mathrm{H}_{8}$, regarding the moderating influences of relationship length and exclusivity, may reflect the strength of the relationship effects. That is, when salespeople are dedicated solely to the supplier's products or have been selling it for more time, they have stronger relationships with the supplier. This relationship strength likely helps them make mental connections and reflect on various issues related to the product, the supplier, and their job or channel requirements. Such reflection should enable them to recognize the relevance of the learning modules they have taken, especially when they write a broad review.

Further considerations. Reviews might be positive or negative, so valence could also have an impact on future learning engagement. We perform exploratory post hoc analyses to investigate this issue, using the data from Studies 2 and 3. Web Appendix 3 contains the results, including the findings about the effect of negative emotional words on learning engagement. Yet review valence does not affect the reported findings or their interpretation, so we do not discuss it further here.

Regarding the potential interdependencies of the study manipulations in Studies 2 and 3, in a study (reported in Web Appendix 4), we analyze the three-way interaction of both manipulations with salespeople's LO. These results indicate that when they write for the benefits of peers, participants with low LO take more modules if they write narrowly; participants with high LO engage in more modules if they write broad reviews. This finding highlights the influence of focusing on similar peers, as well as the need to consider review perspectives and reviewers' learning abilities to predict outcomes (see Web Appendix 4).

\section{General Discussion}

Learning can be an instrument for channel engagementparticularly if learners reflect on their learning experiences, through feedback systems, and develop greater future engagement likelihood. Drawing on self-regulated learning theory, we attribute this drive to review writing, which engages the reviewers, particularly those with low LO, to reflect on the relevance of the learning content to their channel activities, resulting in a heightened pursuit of additional learning (Study 1). Certain types of review writing, for different audiences and with varying levels of focus, also have stronger effects on engagement than others. If reviewers provide a review for similar others, they reflect more on the relevance of the learning, because they believe that peers have similar preferences. This in turn leads to a heightened pursuit of additional learning programs (Study 2). Moreover, if people write with a message focus that matches their LO, it also increases additional learning (Study 3).

\section{Implications for Theory}

This study draws on self-regulated learning theory, yet its theoretical framework, concepts, and implications are grounded in marketing channel literature. In Table 3 we explicate, for each hypothesis, the theoretical perspectives that support our argumentation, highlighting those that are specific to marketing channels.

Beyond these theoretical links to extant research, our findings advance this literature stream. First, by examining feedback systems as tools for engagement, in line with the shift toward relationship marketing in channel contexts (Palmatier 2008), we move beyond a traditional sense that feedback functions only as input that the manufacturer leverages to improve its offerings (Golder, Mitra, and Moorman 2012; Voss et al. 2004). Our research highlights how the very process of review writing relates to self-regulated learning, triggering channel partners to reflect on the relevance of their learning experience, which influences their future learning behaviors. By considering whom they write for and how, we also provide additional support for the presence of metacognition, in that reviewers prompted to consider self-relevant information related to their learning experiences display a higher propensity to complete additional learning modules. We introduce previously unexamined, positive consequences of review writing tasks, thereby opening the theoretical realm to include both direct benefits of feedback (e.g., improved service) and its indirect benefits due to behavioral and motivational transformations. These theoretical implications, identified in a channel context, might emerge in customer-firm relationships, such that feedback systems might help embed customers with the organization too (Bhattacharya and Sen 2003). Leading customers to participate actively with the firm and enter a reflective process may help them recognize the benefits of continued participation and engagement with the organization. Motivating channel partners to undertake actual channel-related activity thus represents an alternative to manufacturers' typical investments in tangible assets, intangible assets, or monetary and nonmonetary incentives (see Table 1). 


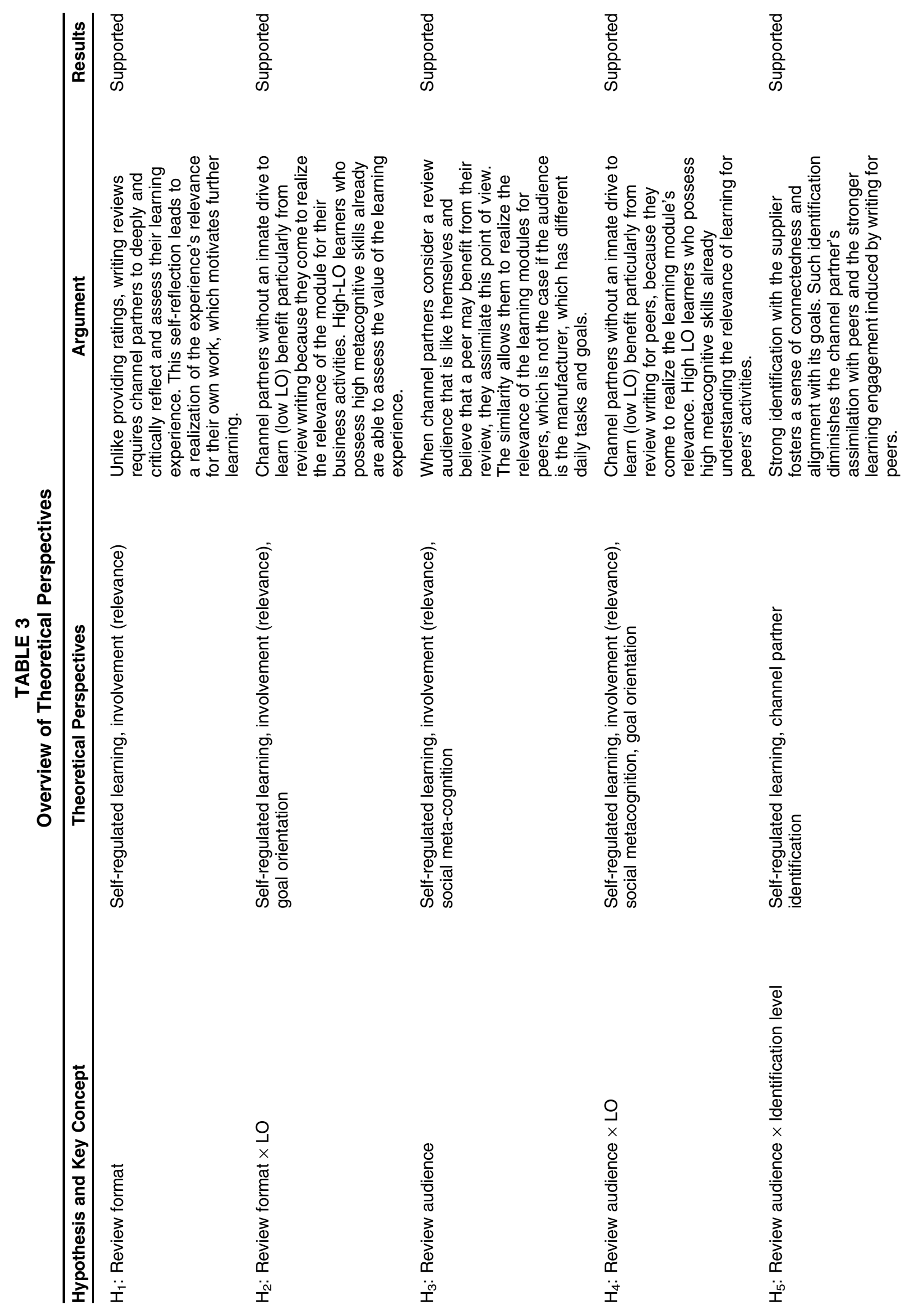




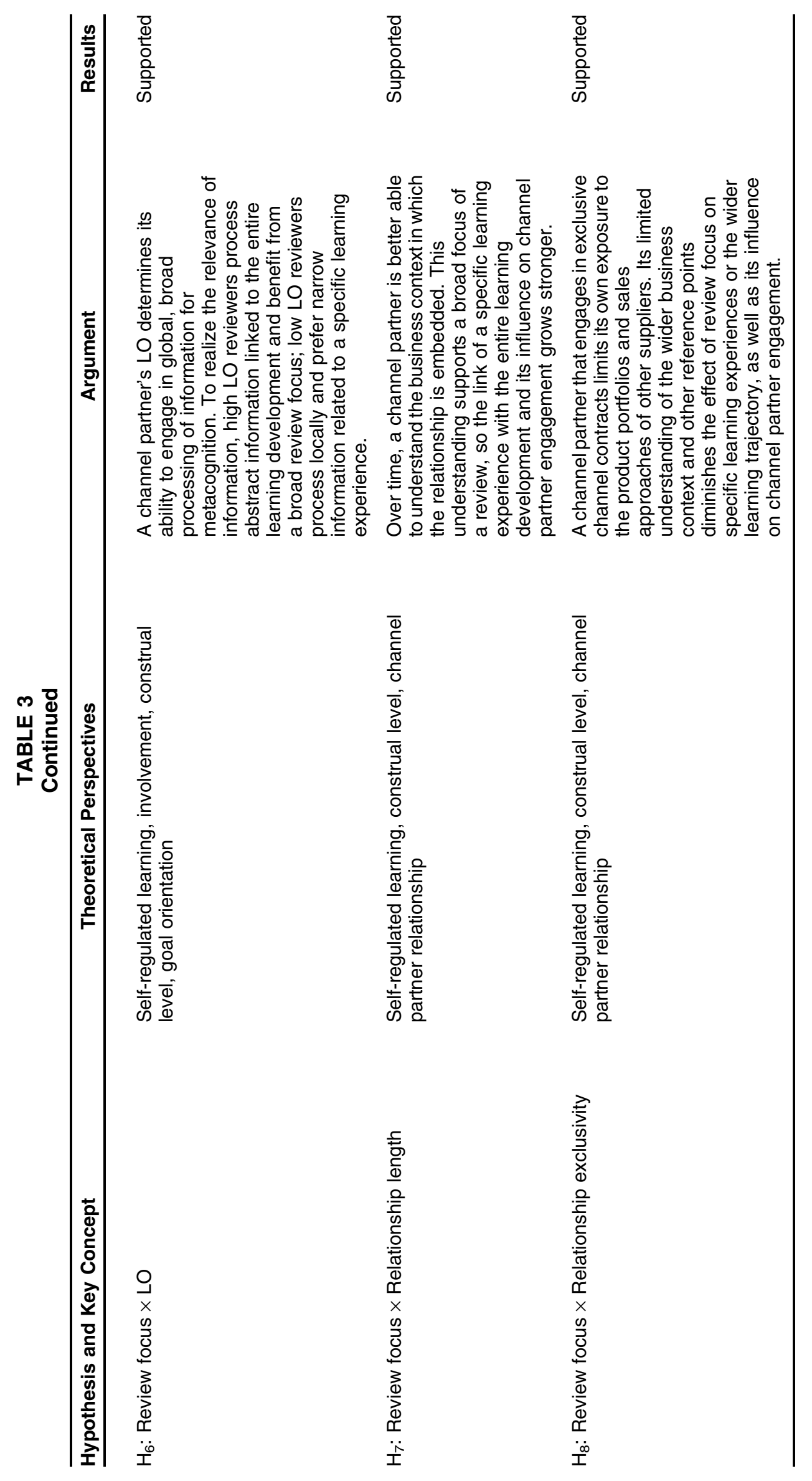


Second, in demonstrating that the self-reflective evaluation of learning experiences drives the effects of review writing on engagement, we extend research on (self-)reflection, beyond considerations of it as a tool to learn (Ellis et al. 2014; Schippers, Homan, and Van Knippenberg 2013). In a channel context, in which manufacturers use training systems to empower sales forces, if salespeople (especially those with low LO) write reviews, they can make better sense of their learning experience and gain a deeper understanding of its benefits. Reflecting on the relevance of the learning experience makes them more willing to engage in additional learning, because they pursue further benefits for their performance in the channel.

Third, though outside the scope of our study, education research has shown that students who reflect on the personal value of class material exhibit increased interest in the course and their class performance (Hulleman and Harackiewicz 2009). With our channel-based study context, we extend this view by including feedback systems that represent subtle rather than explicit demands that learners make connections. Such insights are beneficial, because among professionals, the latter tactic might create backlash.

Fourth, these findings indicate the importance of including reflections about the relevance of the learning experience as mediating mechanisms. Contingent on the audience and focus, these mechanisms help explain channel partners' engagement and the returns of relationship-specific channel investments on financial outcomes. Investments in training programs can build relationship bonds with channel partners and translate into improved sales (Palmatier et al. 2006). However, channel partners need a clear understanding of the value embodied by these relationship-specific investments. These mechanisms can strengthen interorganizational relationships, offering alternatives to efforts that rely solely on trust or commitment (Palmatier, Dant, and Grewal 2007).

\section{Implications for Managers}

By enabling channel partners to meet dynamic growth opportunities in a market, PRM has a strategic influence on manufacturers' overall success. Our findings suggest several ideas for increasing engagement and promoting learning programs, using feedback systems. First, suppliers should incorporate intrinsic motivators to supplement their existing incentive programs. Extrinsic incentives, such as gifts or vacation destinations, might encourage salespeople to participate in learning modules, but they can be easily matched by competitors (Lane ${ }^{4}$ 2013) and generally cannot create truly engaging, meaningful experiences (Palmer, Lunceford, and Patton 2012). Encouraging salespeople to reflect on what they have learned instead helps them understand the relevance of the lessons to their day-to-day activities. Therefore, we recommend that manufacturers incorporate review systems into their learning modules to prompt participants to review modules after taking them. This simple, powerful means to nurture reflective thinking offers notable benefits for channel engagement over time.

Second, channel partners and their employees are heterogeneous, with varying learning motivations and different evaluations of certain rewards (Palmer, Lunceford, and Patton 2012); these traits can signal their willingness to engage in learning programs. Although reflective thinking brought about by writing reviews is a powerful behavioral motivator, its effectiveness seems to differ according to the extent to which the participant is intrinsically motivated to learn. To optimize the behavioral outcomes of reviewing, manufacturers should find ways to focus on essential information-namely, information that is particularly relevant to the personal experience of lower LO partners-in the task instructions. Similar to suggestions put forward by ZS Associates (2014), our results indicate that review tasks should be customized to appeal to different segments of channel partners with distinct needs. For example, manufacturers could identify learners with low LO through a survey question selected from the LO scale, then invite these participants to review modules and highlight the benefits of doing so for peers. As time passes, reviewers may grow accustomed to the learning modules and begin to take them for granted, so the supplier that provides them should specifically ask them to provide a written review for the benefit of their peers or a broad review. Either prompt should lead them to reflect on the relevance of the modules to their business activities and spur them to complete additional learning modules.

Third, manufacturers should emphasize the immediate relevance of any activities that they develop for channel partners. Within learning modules, they might address issues of immediate relevance to these partners, then provide further information that the salespeople can implement directly in their sales pitches. Furthermore, they should strive to translate theory into action, by providing concrete, usable implementation examples.

\section{Limitations and Avenues for Further Research}

This study of how feedback systems can increase individual engagement focuses specifically on engagement in a learning program, which should have cascading effects on objective outcomes, such as sales. However, further research could go beyond a count measure of modules taken to assess learning engagement in different ways, such as the variety of module types taken. It also could address other outcomes that might result from self-regulated learning, such as increased lead generation. This research could be extended to more direct channels as well, wherein firms provide learning programs directly to customers. Beyond learning, other managerially relevant contexts might be considered, such as the impact of feedback systems in businessto-consumer settings (e.g., online customer reviews on ecommerce and social networking sites). Such investigations would enrich theoretical understanding, by providing evidence of whether metacognition drives other engagement behaviors, such as a greater share of wallet or word of mouth.

Continued research might concentrate on motivators other than review writing, such as providing comparative information that benchmarks people's performance on learning tasks against an average or sending trivia questions related to the subject matter to help them think about how much they have learned. We have focused on the effects of review writing after a threemonth period; other research might investigate the dynamic effects of these interventions to detail if and when they diminish over time. Comparative studies of multiple interventions also could shed light on which strategies are most effective for 
engaging partners over time. These insights would provide more delineated understanding of the mechanisms behind the interventions and thus reveal new theoretical knowledge.

Our feedback studies take place within a PRM context. It might be useful to examine whether these effects generalize to other contexts, such as consumer reviews of various service providers (e.g., health portals, restaurants, hotels) and product information provided by retailers and manufacturers. If so, the insights might explain why encouraging review writing (regardless of valence) is beneficial.

Finally, the self-reflective activity of writing reviews drives intrinsic motivations, but in other circumstances, it might trigger external drivers, such as social acceptance, particularly if the review platform enables the writer to showcase him- or herself.
Understanding other motivations associated with writing reviews could expand the theoretical foundations for research in this area, as well as suggest more insightful and sophisticated applications of this simple and effective tool for manufacturers.

Overall, we find that reviewing learning modules can drive learners with low LO to take on additional learning tasks, particularly when they are prompted to consider specific information for the benefit of their peers. We attribute this finding to the activation of metacognition that helps channel partners see the value of the programs. These findings have implications for new methods of engagement, and they also provide a costeffective solution that managers can implement for their partner relationships.

\section{REFERENCES}

Accenture (2010), "Next Generation Partner Relationship Management (PRM): How Collaboration Strategies and Technologies Can Help Electronics and High-Tech Companies Achieve High Performance," (accessed May 1, 2014), http://www. accenture.com.

Ahearne, Michael, C.B. Bhattacharya, and Thomas Gruen (2005), "Antecedents and Consequences of Customer-Company Identification: Expanding the Role of Relationship Marketing," Journal of Applied Psychology, 90 (3), 574-85.

Ahearne, Michael, John Mathieu, and Adam Rapp (2005), "To Empower or Not to Empower Your Sales Force? An Empirical Examination of the Influence of Leadership Empowerment Behavior on Customer Satisfaction and Performance," Journal of Applied Psychology, 90 (5), 945-55.

Ahearne, Michael, Adam Rapp, Douglas E. Hughes, and Rupinder Jindal (2010), "Managing Sales Force Product Perceptions and Control Systems in the Success of New Product Introductions," Journal of Marketing Research, 47 (4), 764-76.

Anderson, Erin, Leonard Lodish, and Barton Weitz (1987), "Resource Allocation Behavior in Conventional Channels," Journal of Marketing Research, 24 (1), 254-62.

Anseel, Frederik, Filip Lievens, and Eveline Schollaert (2009), "Reflection as a Strategy to Enhance Task Performance After Feedback," Organizational Behavior and Human Decision Processes, 110 (1), 23-35.

Antia, Kersi D., Xu (Vivian) Zheng, and Gary L. Frazier (2013), "Conflict Management and Outcomes in Franchise Relationships: The Role of Regulation," Journal of Marketing Research, 50 (5), 577-89.

Applebee, Arthur N. (1984), "Writing and Reasoning," Review of Educational Research, 54 (4), 577-96.

Aron, Arthur, Elaine N. Aron, and Danny Smollan (1992), "Inclusion of Other in the Self Scale and the Structure of Interpersonal Closeness," Journal of Personality and Social Psychology, 63 (4), 596-612.

Badrinarayanan, Vishag, and Debra A. Laverie (2011), "Brand Advocacy and Sales Effort by Retail Salespeople: Antecedents and Influence of Identification with Manufacturers' Brands," Journal of Personal Selling \& Sales Management, 31 (2), 123-40.

Bell, Simon J., Bülent Mengüç, and Robert E. Widing II (2010), "Salesperson Learning, Organizational Learning, and Retail Store Performance," Journal of the Academy of Marketing Science, 38 (2), 187-201.
Bhattacharya, Chitrabhan B., and Sankar Sen (2003), "ConsumerCompany Identification: A Framework for Understanding Consumers' Relationships with Companies," Journal of Marketing, 67 (2), 76-88.

Boud, David, Rosemary Keogh, and David Walker (1985), "Promoting Reflection in Learning: A Model, in "Reflection: Turning Experience into Learning, D. Boud, R. Keogh and D. Walker, eds. London: Kogan Page Ltd., 18-40.

Chase, William G., and K. Anders Ericsson (1981), "Skilled Memory," in Cognitive Skills and Their Acquisition, J.R. Anderson, ed. Hillsdale, NJ: Lawrence Erlbaum Associates, 141-89.

Cho, Kwangsu, and Charles MacArthur (2011), "Learning by Reviewing," Journal of Educational Psychology, 103 (1), 73-84.

Chung, Chiayin, Sharmila C. Chatterjee, and Sanjit Sengupta (2012), "Manufacturers' Reliance on Channel Intermediaries: Value Drivers in the Presence of a Direct Web Channel," Industrial Marketing Management, 41 (1), 40-53.

Cron, William, and John Slocum (1986), "The Influence of Career Stages on Salespeople's Job Attitudes, Work Perceptions, and Performance," Journal of Marketing Research, 23 (2), 119-29.

CSO Insights (2014), “Optimizing Channel Partner Sales Effectiveness," white paper (accessed August 18, 2014), http://www. treehousei.com.

Drewery, Dave, T. Judene Pretti, and Sage Barclay (2016), "Examining the Effects of Perceived Relevance and Work-Related Subjective Well-Being on Individual Performance for Co-Op Students," Asia Pacific Journal of Cooperative Education, 17 (2), 119-34.

Dweck, Carol S. (1986), "Motivational Processes Affect Learning," American Psychologist, 41 (10), 1040-48.

Dweck, Carol S., and Ellen L. Leggett (1988), "A Social-Cognitive Approach to Motivation and Personality," Psychological Review, 95 (2), 256-73.

Elliot, Andrew J., and Marcy A. Church (1997), "A Hierarchical Model of Approach and Avoidance Achievement Motivation," Journal of Personality and Social Psychology, 72 (1), 218-32.

Ellis, Shmuel, Bernd Carette, Frederik Anseel, and Filip Lievens (2014), "Systematic Reflection: Implications for Learning from Failures and Successes," Current Directions in Psychological Science, 23 (1), 67-72.

Ellis, Shmuel, and Inbar Davidi (2005), "After-Event Reviews: Drawing Lessons from Successful and Failed Experience," Journal of Applied Psychology, 90 (5), 857-71. 
Ericsson, K. Anders, and Walter Kintsch (1995), "Long-Term Working Memory," Psychological Review, 102 (2), 211-45.

Fiorletta, Alicia (2012), "Social Media Playing a Starring Role in Partner Marketing," Channel Market Report (March 21), https:// www.channelmarketerreport.com/2012/03/social-media-playinga-starring-role-in-partner-marketing/.

Ford, J. Kevin, Eleanor M. Smith, Daniel A. Weissbein, Stanley M. Gully, and Eduardo Salas (1998), "Relationships of Goal Orientation, Metacognitive Activity and Practice Strategies with Learning Outcomes and Transfer," Journal of Applied Psychology, 83 (2), 218-33.

Förster, Jens (2012), "GLOMO ${ }^{\text {SYS }}$ : The How and Why of Global and Local Processing," Current Directions in Psychological Science, 21 (1), 15-19.

Förster, Jens, and Laura Dannenberg (2010), "GLOMO ${ }^{\text {SYS: A }}$ Systems Account for Global versus Local Processing," Psychological Inquiry, 21 (3), 175-97.

Friedman, Ronald S., and Jens Förster (2005), "Effect of Motivational Cues on Perceptual Asymmetry: Implications for Creativity and Analytical Problem Solving," Journal of Personality and Social Psychology, 88 (2), 263-75.

Gammoh, Bashar S., Michael L. Mallin, and Ellen B. Pullins (2014), "Antecedents and Consequences of Salesperson Identification with the Brand and the Company," Journal of Personal Selling \& Sales Management, 34 (1), 3-18.

Gilliland, David I., Daniel C. Bello, and Gregory T. Gundlach (2010), "Control-Based Channel Governance and Relative Dependence," Journal of the Academy of Marketing Science, 38 (4), 441-55.

Gilliland, David I., and Stephen K. Kim (2014), "When Do Incentives Work in Channels of Distribution?" Journal of the Academy of Marketing Science, 42 (4), 361-79.

Glogger, Inga, Rolf Schwonke, Lars Holzäpfel, Natthias Nückles, and Alexander Renkl (2012), "Learning Strategies Assessed by Journal Writing: Prediction of Learning Outcomes by Quantity, Quality, and Combinations of Learning Strategies," Journal of Educational Psychology, 104 (2), 452-68.

Golder, Peter N., Debanjan Mitra, and Christine Moorman (2012), "What Is Quality? An Integrative Framework of Processes and States," Journal of Marketing, 76 (4), 1-23.

Grant, Anthony M., John Franklin, and Peter Langford (2002), "The Self-Reflection and Insight Scale: A New Measure of Private SelfConsciousness," Social Behavior and Personality, 30 (8), 821-35.

Haber, Lynn (2016), "HPE Refreshes Partner Ready Program," Channel Partners Online (September 12), http://www.channelpartnersonline.com/2016/09/12/hpe-refreshes-partner-ready-program/.

Harmon, Tim, Tirthankar Sen, Peter O'Neill, William Band, and TyleVr Otte (2013), "The Forrester Wave $\mathrm{TM}_{\mathrm{M}}$ : Partner Relationship Management (PRM) Platforms, Q4 2013," Forrester (November 22), https://www.forrester.com/report/The+Forrester+ Wave+Partner+Relationship+Management+PRM+Platforms+Q4+ 2013/-/E-RES91761.

Harris, Eric G., John C. Mowen, and Tom J. Brown (2005), "ReExamining Salesperson Goal Orientations: Personality Influences, Customer Orientation, and Work Satisfaction," Journal of the Academy of Marketing Science, 33 (1), 19-35.

Hayes, Andrew F. (2013), Introduction to Mediation, Moderation, and Conditional Process Analysis: A Regression-Based Approach. New York: Guilford Press.

Hennessy, Bill, Nicki Powers, and Barry Kirk (2012), "The Power of Play: How Gamification Will Drive the Evolution of Channel Loyalty," Maritz, https://www.maritz.com/ /media/Files/ MaritzDotCom/White\%20Papers/Motivation/The-Power-of-Play_ How-Gamification-Will-Drive-the-Evolution-of-Channel-Loyalty. ashx.
Hughes, Douglas E., and Michael Ahearne (2010), "Energizing the Reseller's Sales Force: The Power of Brand Identification," Journal of Marketing, 74 (July), 81-96.

Hulleman, Chris S., and Judith M. Harackiewicz (2009), "Promoting Interest and Performance in High School Science Classes," Science, 326 (5958), 1410-12.

Jacobs, Janis E., and Scott G. Paris (1987), “Children's Metacognition About Reading: Issues in Definition, Measurement, and Instruction," Educational Psychologist, 22 (3\&4), 255-78.

Jost, John T., Arie W. Kruglanski, and Thomas O. Nelson (1998), "Social Metacognition: An Expansionist Review," Personality and Social Psychology Review, 2 (2), 137-54.

Kashyap, Vishal, Kersi D. Antia, and Gary L. Frazier (2012), "Contracts, Extracontractual Incentives, and Ex Post Behavior in Franchise Channel Relationships," Journal of Marketing Research, 49 (2), 260-76.

Kim, Daekwan, S. Tamer Cavusgil, and Roger J. Calantone (2006), "Information System Innovations and Supply Chain Management: Channel Relationships and Firm Performance," Journal of the Academy of Marketing Science, 34 (1), 40-54.

Klein, Perry D. (1999), "Reopening Inquiry into Cognitive Processes in Writing-To-Learn," Educational Psychology Review, 11 (3), 203-70.

Kohli, Ajay K., Tasadduq A. Shervani, and Goutam N. Challagalla (1998), "Learning and Performance Orientation of Salespeople: The Role of Supervisors," Journal of Marketing Research, 35 (May), 263-74.

Koza, Karen L., and Rajiv P. Dant (2007), "Effects of Relationship Climate, Control Mechanism, and Communications on Conflict Resolution Behavior and Performance Outcomes," Journal of Retailing, 83 (3), 279-96.

Krishnamurthy, Parthasarathy, and Anuradha Sivaraman (2002), "Counterfactual Thinking and Advertising Responses," Journal of Consumer Research, 28 (4), 650-58.

Kuhrt, Bonnie L., and Pamela J. Farris (1990), "Empowering Students Through Reading, Writing, and Reasoning," Journal of Reading, 33 (6), 436-41.

Kyung, Ellie J., Geeta Menon, and Yaacov Trope (2014), “Construal Level and Temporal Judgments of the Past: The Moderating Role of Knowledge," Psychonomic Bulletin \& Review, 21 (3), 734-39.

Lane $^{4}$ (2013), "Talent Tactics: How Can You Plug the Talent Gap?" white paper (February 17), http://www.lane4performance.com/ insight/whitepaper/talent-tactics-how-can-you-plug-the-talent-gap/.

Lerouge, Davy, and Luk Warlop (2006), "Why It Is So Hard to Predict Our Partner's Product Preferences? The Effect of Target Familiarity on Prediction Accuracy," Journal of Consumer Research, 33 (3), 393-402.

Li, Lan, Xiongyi Liu, and Allen L. Steckelberg (2010), “Assessor or Assessee: How Student Learning Improves by Giving and Receiving Peer Feedback," British Journal of Educational Technology, 41 (3), 525-36.

Long, J. Scott, and Jeremy Freese (2006), Regression Models for Categorical and Limited Dependent Variables Using Stata. College Station, TX: Stata Press.

Ludwig, S., Ko de Ruyter, M. Friedman, Elisabeth C. Bruggen, Martin Wetzels, and G. Pfann (2013), "More Than Words: The Influence of Affective Content and Linguistic Style Matches in Online Reviews on Conversion Rates," Journal of Marketing, 77 (1), 87-103.

Mael, Fred, and Blake E. Ashforth (1992), “Alumni and Their Alma Mater: A Partial Test of the Reformulated Model of Organizational Identification," Journal of Organizational Behavior, 13 (2), 103-23. 
Magnifico, Alecia Marie (2010), "Writing for Whom? Cognition, Motivation, and a Writer's Audience," Educational Psychologist, 45 (3), 167-84.

Miller, Raymond B., and Stephanie J. Brickman (2004), “A Model of Future-Oriented Motivation and Self-Regulation," Educational Psychology Review, 16 (1), 9-33.

Muller, Dominique, Charles M. Judd, and Vincent Y. Yzerbyt (2005), "When Moderation Is Mediated and Mediation Is Moderated," Journal of Personality and Social Psychology, 89 (6), 852-63.

Naylor, Rebecca Walker, Cait Poynor Lamberton, and David A. Norton (2011), "Seeing Ourselves in Others: Reviewer Ambiguity, Egocentric Anchoring, and Persuasion," Journal of Marketing Research, 48 (3), 617-31.

Palmer, Doug, Steve Lunceford, and Aaron J. Patton (2012), "The Engagement Economy: How Gamification in Reshaping Business," Deloitte Insights (July 1), https://www2.deloitte.com/insights/ us/en/deloitte-review/issue-11/the-engagement-economyhow-gamification-is-reshaping-businesses.html.

Palmatier, Robert W. (2008), Relationship Marketing. Cambridge, MA: Marketing Science Institute.

Palmatier, Robert W., Rajiv P. Dant, and Dhruv Grewal (2007), “A Comparative Longitudinal Analysis of the Theoretical Perspectives of Interorganizational Relationship Performance," Journal of Marketing, 71 (4), 172-94.

Palmatier, Robert W., Rajiv P. Dant, Dhruv Grewal, and Kenneth R. Evans (2006), "Factors Influencing the Effectiveness of Relationship Marketing: A Meta-Analysis," Journal of Marketing, 70 (4), 136-53.

Pelser, Jan, Ko de Ruyter, Martin Wetzels, Dhruv Grewal, David Cox, and Jacqueline van Beuningen (2015), "B2B Channel Partner Programs: Disentangling Indebtedness from Gratitude," Journal of Retailing, 91 (4), 660-78.

Pintrich, Paul R. (2004), "A Conceptual Framework for Assessing Motivation and Self-Regulated Learning in College Students," Educational Psychology Review, 16 (4), 385-407.

Ramaswami, Sridhar N., and S. Arunachalam (2016), "Divided Attitudinal Loyalty and Customer Value: Role of Dealers in an Indirect Channel," Journal of the Academy of Marketing Science, 44 (6), 770-90.

Richey, R. Glenn, Mert Tokman, and Vivek Dalela (2010), "Examining Collaborative Supply Chain Service Technologies: A Study of Intensity, Relationships, and Resources," Journal of the Academy of Marketing Science, 38 (1), 71-89.

Scheer, Lisa K., and Louis W. Stern (1992), "The Effect of Influence Type and Performance Outcomes on Attitude Toward the Influencer," Journal of Marketing Research, 29 (1), 128-42.

Schippers, Michaéla C., Astrid C. Homan, and Daan van Knippenberg (2013), "To Reflect or Not to Reflect: Prior Team Performance as a Boundary Condition of the Effects of Reflexivity on Learning and Final Team Performance," Journal of Organizational Behavior, 34 (1), 6-23.

Schmidt, Aaron M., and J. Kevin Ford (2003), "Learning Within a Learner Control Training Environment: The Interactive Effects of Goal Orientation and Metacognitive Instruction on Learning Outcomes," Personnel Psychology, 56 (2), 405-29.

Schunk, Dale H. (2005), "Self-Regulated Learning: The Educational Legacy of Paul R. Pintrich," Educational Psychologist, 40 (2), 85-94.

Sheldon, Oliver J., David Dunning, and Daniel R. Ames (2014), "Emotionally Unskilled, Unaware, and Uninterested in Learning More: Reactions to Feedback About Deficits in Emotional Intelligence," Journal of Applied Psychology, 99 (1), 125-37.
Sitzmann, Traci, and Katherine Ely (2010), "Sometimes You Need a Reminder: The Effects of Prompting Self-Regulation on Regulatory Process, Learning, and Attrition," Journal of Applied Psychology, 95 (1), 132-44.

Somuncuoglu, Yesim, and Ali Yildirim (1999), "Relationship Between Achievement Goal Orientations and Use of Learning Strategies," Journal of Educational Research, 92 (5), 267-77.

Song, Michael, C. Anthony Di Benedetto, and Yushan Zhao (2008), "The Antecedents and Consequences of ManufacturerDistributor Cooperation: An Empirical Test in the US and Japan," Journal of the Academy of Marketing Science, 36 (2), 215-33.

Spiller, Stephen A., Gavan J. Fitzsimons, John G. Lynch, and Gary H. McClelland (2013), "Spotlights, Floodlights, and the Magic Number Zero: Simple Effects Tests in Moderated Regression," Journal of Marketing Research, 50 (2), 277-88.

Sujan, Harish, Barton A. Weitz, and Nirmalya Kumar (1994), "Learning Orientation, Working Smart, and Effective Selling," Journal of Marketing, 58 (3), 39-52.

The New York Times (2011), "The Psychology of Sharing," white paper (October), http://www.iab.net/media/file/POSWhitePaper.pdf.

Veenman, Marcel V.J., Bernadette H.A.M. van Hout-Wolters, and Peter Afflerbach (2006), "Metacognition and Learning: Conceptual and Methodological Considerations," Metacognition and Learning, 1 (1), 3-14.

Villado, Anton J., and Winfred Arthur Jr. (2013), "The Comparative Effect of Subjective and Objective After-Action Reviews on Team Performance on a Complex Task," Journal of Applied Psychology, 98 (3), 514-28.

Voss, Christopher A., Aleda V. Roth, Eve D. Rosenzweig, Kate Blackmon, and Richard B. Chase (2004), "A Tale of Two Countries' Conservatism, Service Quality, and Feedback on Customer Satisfaction," Journal of Service Research, 6 (3), 212-30.

Vuong, Quang H. (1989), "Likelihood Ratio Tests for Model Selection and Non-Nested Hypotheses," Econometrica, 57 (2), 307-33.

Wang, Guangping, and Richard G. Netemeyer (2002), "The Effects of Job Autonomy. Customer Demandingness, and Trait Competitiveness on Salesperson Learning, Self-Efficacy, and Performance," Journal of the Academy of Marketing Science, 30 (3), 217-28.

Wieseke, Jan, Anja Geigenmüller, and Florian Kraus (2012), "On the Role of Empathy in Employee-Customer Interactions," Journal of Service Research, 15 (3), 316-31.

Williams, Richard (2012), "Using the Margins Command to Estimate and Interpret Adjusted Predictions and Marginal Effects," Stata Journal, 12 (2), 308-31.

Zaichkowsky, Judith L. (1994), "The Personal Involvement Inventory: Reduction, Revision, and Application to Advertising," Journal of Advertising, 23 (4), 59-70.

Zhao, Xinshu, John G. Lynch Jr., and Qimei Chen (2010), "Reconsidering Baron and Kenny: Myths and Truths About Mediation Analysis," Journal of Consumer Research, 37 (August), 197-206.

Zimmerman, Barry J. (2002), "Becoming a Self-Regulated Learner: An Overview," Theory into Practice, 41 (2), 64-70.

Zimmerman, Barry J., and Dale H. Schunk (2001), SelfRegulated Learning and Academic Achievement: Theoretical Perspectives, 2nd ed. Mahwah, NJ: Lawrence Erlbaum Associates.

ZS Associates (2014), "Voice of Partner Programs from Hardware to Software Companies Leave Many IT Channels Flat," (April 2), https://www.zs.com/about/news-and-events/news/voice-of-partnerprograms-from-hardware-and-software-companies-leave-many-itchannel-partners-flat.aspx. 